Check for updates

Cite this: Phys. Chem. Chem. Phys., 2021, 23, 5496

\title{
Theoretical and experimental study of peroxy and alkoxy radicals in the $\mathrm{NO}_{3}$-initiated oxidation of isoprene $\dagger$
}

\author{
L. Vereecken, (D)*a P. T. M. Carlsson, (D) a A. Novelli, (D) ${ }^{a}$ F. Bernard, $\ddagger^{b}$

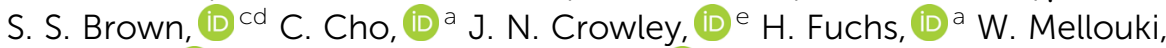

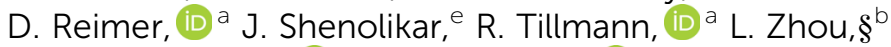 \\ A. Kiendler-Scharr (iD ${ }^{a}$ and A. Wahner (iD) ${ }^{a}$
}

\begin{abstract}
The initial stages of the nitrate radical $\left(\mathrm{NO}_{3}\right)$ initiated oxidation of isoprene, in particular the fate of the peroxy $\left(\mathrm{RO}_{2}\right)$ and alkoxy $(\mathrm{RO})$ radicals, are examined by an extensive set of quantum chemical and theoretical kinetic calculations. It is shown that the oxidation mechanism is highly complex, and bears similarities to its $\mathrm{OH}$-initiated oxidation mechanism as studied intensively over the last decade. The nascent nitrated $\mathrm{RO}_{2}$ radicals can interconvert by successive $\mathrm{O}_{2}$ addition/elimination reactions, and potentially have access to a wide range of unimolecular reactions with rate coefficients as high as $35 \mathrm{~s}^{-1}$; the contribution of this chemistry could not be ascertained experimentally. The chemistry of the alkoxy radicals derived from these peroxy radicals is affected by the nitrate moiety, and can lead to the formation of nitrated epoxy peroxy radicals in competition with isomerisation and decomposition channels that terminate the organic radical chain by $\mathrm{NO}_{2}$ elimination. The theoretical predictions are implemented in the $\mathrm{FZJ}-\mathrm{NO}_{3}$-isoprene mechanism for $\mathrm{NO}_{3}$-initiated atmospheric oxidation of isoprene. The model predictions are compared against peroxy radical $\left(\mathrm{RO}_{2}\right)$ and methyl vinyl ketone $(\mathrm{MVK})$ measurements in a set of experiments on the isoprene $+\mathrm{NO}_{3}$ reaction system performed in the SAPHIR environmental chamber (IsopNO 3 campaign). It is shown that the formation of $\mathrm{NO}_{2}$ from the peroxy radicals can prevent a large fraction of the peroxy radicals from being measured by the laser-induced fluorescence (ROxLIF) technique that relies on a quantitative conversion of peroxy radicals to hydroxyl radicals. Accounting for the relative conversion efficiency of $\mathrm{RO}_{2}$ species in the experiments, the agreement between observations and the theory-based $\mathrm{FZJ}_{-} \mathrm{NO}_{3}$-isoprene model predictions improves significantly. In addition, $\mathrm{MVK}$ formation in the $\mathrm{NO}_{3}$-initiated oxidation was found to be suppressed by the epoxidation of the unsaturated $\mathrm{RO}$ radical intermediates, allowing the model-predicted MVK concentrations to be in good agreement with the measurements. The $\mathrm{FZJ}-\mathrm{NO}_{3}$-isoprene mechanism is compared against the MCM v3.3.1 and Wennberg et al. (2018) mechanisms.
\end{abstract}

Received 3rd December 2020, Accepted 8th February 2021

DOI: $10.1039 / \mathrm{dOcp06267g}$

rsc.li/pccp half of the mass of non-methane VOCs released. ${ }^{1}$ Its tropospheric oxidation is predominantly initiated by hydroxyl $(\mathrm{OH})$ radicals during the daytime, but at nighttime the lack of photolytic sources of $\mathrm{OH}$ shifts the main initiation channels to the nitrate radical, atmo volile organic compounds (VOCs) emitted to the

\footnotetext{
${ }^{a}$ Institute for Energy and Climate Research, Forschungszentrum Jülich GmbH, 52428 Jülich, Germany. E-mail: l.vereecken@fz-juelich.de

${ }^{b}$ Institut de Combustion, Aérothermique, Réactivité et Environnement (ICARE), CNRS (UPR 3021)/OSUC, 1C Avenue de la Recherche Scientifique, 45071 Orléans CEDEX 2, France

${ }^{c}$ NOAA Chemical Sciences Laboratory, 325 Broadway, Boulder, CO 80305, USA

${ }^{d}$ Department of Chemistry, University of Colorado Boulder, Boulder, CO 80209, USA

${ }^{e}$ Atmospheric Chemistry Department, Max-Planck-Institut für Chemie, 55128 Mainz, Germany

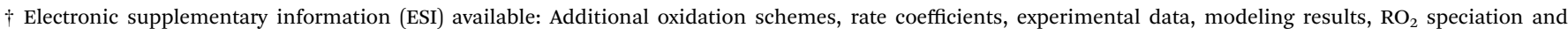

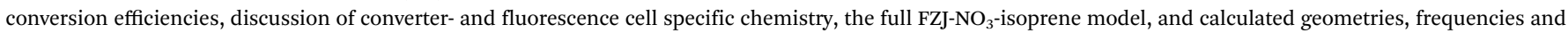
energies for all intermediates and transition states. See DOI: $10.1039 / \mathrm{d} 0 \mathrm{cp} 06267 \mathrm{~g}$

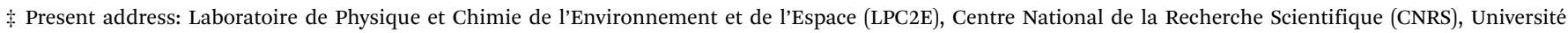
d'Orléans, Observatoire des Sciences de l'Univers en Région Centre - Val de Loire (OSUC), Orléans, France.

$\S$ Present address: College of Architecture and Environment, Sichuan University, Chengdu, China.
} 
$\mathrm{NO}_{3}$, and ozone, $\mathrm{O}_{3} \cdot{ }^{2-6}$ Although isoprene emissions are predominantly biogenic and light-driven, residual isoprene is left during the night, allowing a sizable fraction of the emitted isoprene to be oxidized by $\mathrm{NO}_{3}$ in the nocturnal boundary layer. ${ }^{7-9}$ Furthermore, under some conditions $\mathrm{NO}_{3}$ oxidation can still contribute for a sizable fraction to daytime atmospheric VOC oxidation. ${ }^{10,11}$

The $\mathrm{OH}$-initiated reaction of isoprene has been well-studied, where the last decade has seen many studies examining the complex oxidation pathways, the formation of oxygenated products, and the regeneration of $\mathrm{OH}$ radicals. ${ }^{4,12-22}$ The oxidation was shown to comprise a rapidly branching mechanism where correct treatment of the site-specificity of the initial $\mathrm{OH}$ addition and subsequent (reversible) $\mathrm{O}_{2}$ addition is critical:

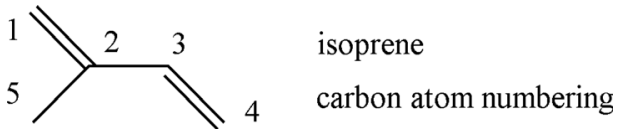

$$
\text { isoprene }+\mathrm{OH} \rightarrow \text { HO-isoprene radicals (4 isomers) }
$$

$$
\text { HO-isoprene }+\mathrm{O}_{2} \leftrightarrow \text { HO-isoprene-OO` peroxy radicals }
$$

$$
\text { (8 isomers) }
$$

The product speciation is sensitive to the rate of unimolecular reactions of the peroxy radicals $\left(\mathrm{RO}_{2}\right)$ formed, i.e. redissociation by $\mathrm{O}_{2}$ loss or isomerisation by $\mathrm{H}$-migration, in competition with more traditional bimolecular reaction of these $\mathrm{RO}_{2}$ with $\mathrm{NO}$, $\mathrm{NO}_{3}, \mathrm{HO}_{2}$ and $\mathrm{R}^{\prime} \mathrm{O}_{2}$ co-reactants. Due to the critical role of unimolecular $\mathrm{RO}_{2}$ reactions in $\mathrm{OH} / \mathrm{HO}_{x}$ regeneration, the formation of highly oxidized organic molecules (HOMs), and of low-volatility compounds partitioning to the aerosol phase, these reactions have received significant attention in recent years, both for isoprene and for other VOCs. ${ }^{23-33}$
Although the reaction of the $\mathrm{NO}_{3}$ radical with isoprene can be expected to show the same complexity and to proceed through similar pathways, currently available mechanisms such as the Master Chemical Mechanism ${ }^{34-36}$ or the recent model by Wennberg et al. ${ }^{4}$ tend to include only a simplified version with a selected set of intermediates. Similar to the $\mathrm{OH}$-initiated oxidation though, analyses based on the full branched reaction mechanism are necessary to elucidate the chemistry, and to decide which reactions can be omitted in specific reaction conditions. As indicated in a recent perspective on mechanism development, ${ }^{37}$ the formulation of such (near-)explicit models is an important tool in tackling modern challenges facing atmospheric sciences. Literature data ${ }^{38}$ suggests that nitrate substitution leads to slower radical chemistry compared to $\mathrm{OH}$-substitution, and the relative importance of the individual channels can be expected to be different between $\mathrm{OH}$ - and $\mathrm{NO}_{3}$-initiated isoprene chemistry. A recent review by Wennberg et al. ${ }^{4}$ gives a good overview of the status quaestionis of isoprene oxidation by $\mathrm{OH}$ and $\mathrm{NO}_{3}$, based on the available literature on the $\mathrm{NO}_{3}$-initiated oxidation of isoprene up to now. ${ }^{39-48}$

In this work, we investigate several aspects of the first stages of the $\mathrm{NO}_{3}$-initiated oxidation of isoprene, and of measurements of nitrated $\mathrm{RO}_{2}$ radicals, as summarized in Fig. 1. First, we present a combined theoretical and experimental study on the initial steps in the isoprene $+\mathrm{NO}_{3}+\mathrm{O}_{2}$ reaction mechanism, i.e. the formation and destruction of the initial set of 8 nitrated alkylperoxy radical isomers (called nitrate- $\mathrm{RO}_{2}$ hereafter). The subsequent chemistry of the isoprene- $\mathrm{NO}_{3}$ alkylperoxy and alkoxy radicals is likewise examined in detail. Their fate as governed by the competition between unimolecular and bimolecular reactions is important not only for the atmospheric chemistry of isoprene, but also plays a critical role in the experimental detection of the nitrate- $\mathrm{RO}_{2}$ radicals by a ROxLIF instrument. For the latter, we extend the

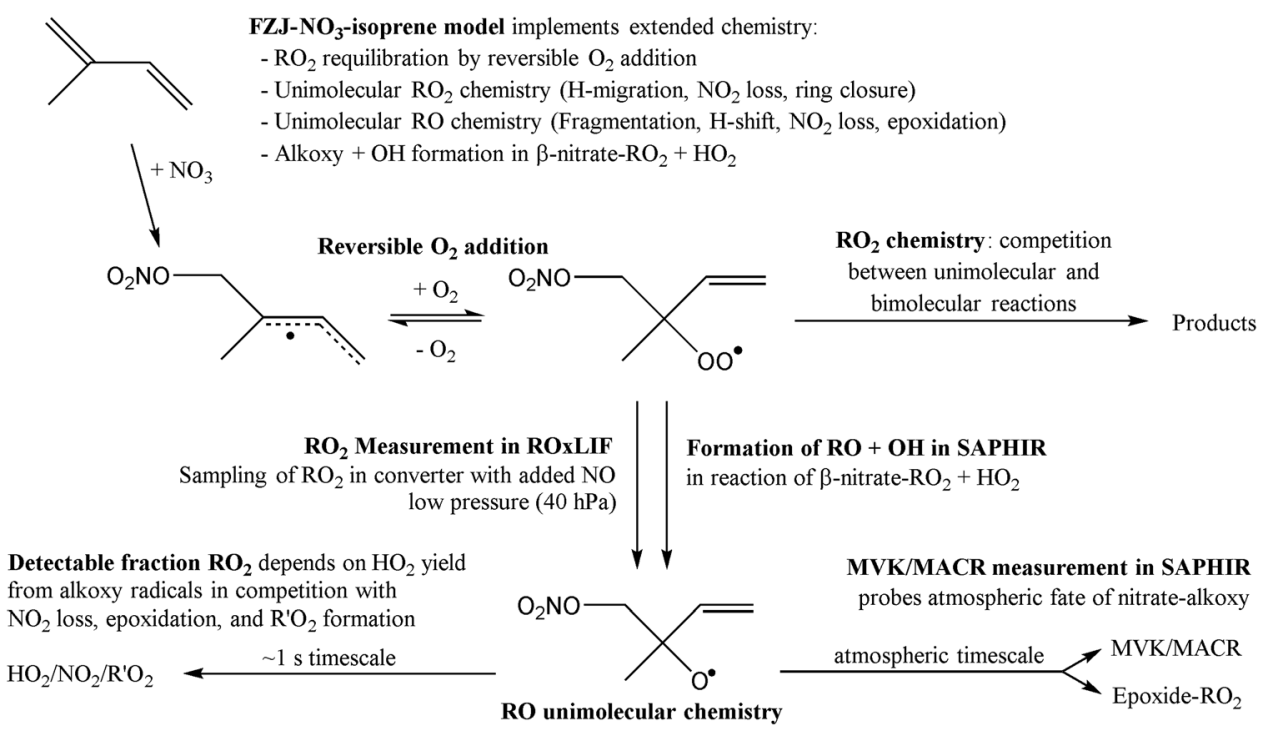

Fig. 1 Summarizing scheme showing the investigated steps, which includes the $\mathrm{NO}_{3}$ and (reversible) $\mathrm{O}_{2}$ addition (site- and stereospecificity omitted), unimolecular chemistry of the nitrate peroxy and alkoxy radicals, and interpretation of the experimental $\mathrm{RO}_{2}$ and $M V K / M A C R$ measurements. All chemistry is implemented in the $\mathrm{FZJ}-\mathrm{NO}_{3}$-isoprene model. 
recent work by Novelli et al. ${ }^{49}$ on nitrate-substituted alkoxy radicals (called nitrate-RO hereafter) to the nitrate-RO derived from isoprene. The chemistry of these unsaturated alkoxy radicals can proceed by reversible epoxidation and subsequent $\mathrm{O}_{2}$ capture, which affects both the detection of $\mathrm{RO}_{2}$ in the ROxLIF instrument, and the yield of MVK and MACR in the SAPHIR chamber and the atmosphere. The chemistry characterized is implemented in the $\mathrm{FZJ}-\mathrm{NO}_{3}$-isoprene model.

\section{Methodologies}

\subsection{Theoretical methodology}

The nitrate- $\mathrm{RO}_{2}$ and nitrate- $\mathrm{RO}$ radicals derived from isoprene $+\mathrm{NO}_{3}$ were first optimized using the M06-2X/cc-pVDZ level of quantum chemical theory, ${ }^{50,51}$ characterizing all conformers of reactants and transition states for the reactions studied. The resulting geometries were re-optimized at the M06-2X/aug-ccpVTZ level of theory, ${ }^{50}$ and combined with single point energy calculations on the lowest conformers at the $\operatorname{CCSD}(\mathrm{T}) / \mathrm{aug}$-ccpVTZ level of theory. ${ }^{52} \mathrm{ZPE}$ corrections are done at the M06-2X/ aug-cc-pVTZ level of theory, with vibrational wavenumbers scaled by $0.971 .^{53,54}$ All quantum chemical calculations were performed using the Gaussian-16 software suites. ${ }^{55}$

The rate coefficients of the reactions are obtained using multi-conformer transition state theory, MC-TST, ${ }^{56,57}$ incorporating the characteristics of all conformers in a rigid rotor harmonic oscillator approximation, as obtained at the $\operatorname{CCSD}(\mathrm{T}) /$ aug-cc-pVTZ//M06-2X/aug-cc-pVTZ level of theory. Tunneling is included using an asymmetric Eckart barrier correction. ${ }^{58,59}$ At the chosen level of theory used here, the rate coefficients are expected to have an accuracy of a factor of 2 to 4 . We also compare the rate coefficient predictions against available structureactivity relationships (SARs) for alkoxy decomposition ${ }^{38,49}$ and $\mathrm{H}$-migration, ${ }^{60}$ and $\mathrm{RO}_{2}$ radical $\mathrm{H}$-migration. ${ }^{33}$ The analysis of nitrate- $\mathrm{RO}_{2}$ thermal equilibrium population was likewise based on the ratios of the multi-conformer $\mathrm{RO}_{2}$ partition functions. The method for calculating bulk rate coefficients across rapidly equilibrating groups of reactants is already described for conformer and isomer equilibration by internal rotation ${ }^{61}$ or $\mathrm{H}$-migration; ${ }^{27,33}$ it is also applicable $\mathrm{e}^{12,13}$ to $\mathrm{RO}_{2}$ populations equilibrated by $\mathrm{O}_{2}$ addition/elimination as in the nitrate- $\mathrm{RO}_{2}$ radicals discussed in this work. Note that the rate of $\mathrm{O}_{2}$ addition forming the $\mathrm{RO}_{2}$ intermediates, and their reverse $\mathrm{O}_{2}$ elimination reactions, cannot be predicted a priori with the necessary accuracy for the task at hand, owing to the difficulties in characterizing the (near-)barrierless transition state on the flat potential energy surface for recombination of a doublet radical with a triplet biradical. We will thus base our analysis for the $\mathrm{R}$ to $\mathrm{RO}_{2}$ interconversion on the more reliable equilibrium constants, as discussed below.

The (de-)epoxidation reactions characterized in this work are fast, nearing the collision limit, and deviations from the Boltzmann distribution might occur. Any chemical activation effects depend on temperature, pressure, and the bath gas, and would be different for each source reaction of the epoxidizing alkoxy radical as formed from the parent $\mathrm{RO}_{2}$ radical reacting with $\mathrm{NO}, \mathrm{NO}_{3}, \mathrm{HO}_{2}$ and each of the individual $\mathrm{R}^{\prime} \mathrm{O}_{2}$. Nguyen and Peeters ${ }^{21}$ examined the reaction rate of a similar epoxidation reaction based on energy-specific versus Boltzmann population based paradigms, but found only small differences. A second important criterion for thermalization is the rate of effective loss of conformers out of the epoxidation systems. In this work, these are unimolecular reactions and recombination with $\mathrm{O}_{2}$ removing the interconverting alkoxy and epoxy-alkyl radicals. The effective loss rates are typically slower than the (de-)epoxidation reactions, allowing for substantially more collisions than would be expected solely from the (de-)epoxidation rates, and hence provide better adherence to the thermal Boltzmann distribution across all conformers. To estimate the impact of chemical activation, we examined the fraction of prompt decomposition of $1-\mathrm{NO}_{3}$ isoprene-2- $\mathrm{O}^{\bullet}$ radicals, the main alkoxy radical in our system, to $\mathrm{MVK}+\mathrm{NO}_{2}$ (see ESI $\dagger$ ). ${ }^{62}$ At 1 bar as in the SAPHIR chamber, we find that prompt decomposition is negligible, and all of the 1- $\mathrm{NO}_{3}$-isoprene-2-O ${ }^{\bullet}$ radicals form epoxy-peroxy radicals. At 25 mbar, we find some prompt decomposition only at internal energies above $17 \mathrm{kcal} \mathrm{mol}^{-1}$, and reaching a contribution of $10 \%$ only at $21 \mathrm{kcal} \mathrm{mol}^{-1}$, while the internal energy is estimated to be on average less than that. As such, we estimate that chemical activation effects are not overly critical, and the product distributions predicted in this work are sufficiently accurate even if the absolute rate coefficient may carry a somewhat larger uncertainty, and the predicted detectability of the nitrate- $\mathrm{RO}_{2}$ are likely somewhat overestimated. Quantifying the chemical activation effects, even in the low-pressure converter, are thus considered outside the scope of this work.

\subsection{Experimental methodology}

The experiments described here were part of a larger campaign on the $\mathrm{NO}_{3}$-initiated oxidation of isoprene (IsopNO $\mathrm{N}_{3}$ campaign) conducted in the atmospheric simulation chamber SAPHIR. More details about the campaign can be found in Dewald et al. ${ }^{46}$ The SAPHIR chamber is made of a double-wall Teflon (FEP) film that is inert, and is kept under slightly higher than ambient pressure (by $\sim 30 \mathrm{~Pa}$ ) to avoid external air penetrating the chamber. Due to small leakages and air consumption by instruments, a steady replenishment flow keeps the overpressure constant, causing trace gases to be diluted at ate of $\sim 6 \% \mathrm{~h}^{-1}$. More details regarding the chamber can be found elsewhere. ${ }^{63-65}$

For all three experiments described within this study, the chamber was cleaned before each experiment by flushing with more than 6 times its volume with ultra-pure synthetic air provided by mixing nitrogen and oxygen (Linde, >99.99990\%). Isoprene, $\mathrm{O}_{3}$ and $\mathrm{NO}_{2}$ were injected several times over the course of one experiment. Between 1.8 and $6 \mathrm{ppbv}$ of isoprene were injected directly from the liquid (99\% purity, Sigma Aldrich), while $\mathrm{O}_{3}$ was produced by a silent discharge ozonizer (O3onia) and added to reach concentrations between 40 and 110 ppbv. $\mathrm{NO}_{2}$ was added via calibrated flow controllers as a dilution of $519 \mathrm{ppm}$ in $\mathrm{N}_{2}$ for concentrations between 3 and 25 ppbv. Two fans in the chamber ensure complete mixing of trace gases 
within 2 min. The $\mathrm{NO}_{3}$ oxidant is formed rapidly in the reaction of $\mathrm{O}_{3}$ with $\mathrm{NO}_{2}$ :

$$
\mathrm{NO}_{2}+\mathrm{O}_{3} \rightarrow \mathrm{NO}_{3}+\mathrm{O}_{2}
$$

Concentrations of $\mathrm{HO}_{2}$ and $\mathrm{RO}_{2}$ radicals were measured with the laser-induced fluorescence (LIF) instrument permanently in use at the SAPHIR chamber and described previously. ${ }^{66,67}$ Briefly: the instrument measures $\mathrm{HO}_{2}$ by conversion to $\mathrm{OH}$ radicals in the fluorescence cell ( $\sim 4 \mathrm{hPa})$ by reaction with NO. Several studies ${ }^{67,68}$ have highlighted how $\mathrm{RO}_{2}$ radicals can interfere with the $\mathrm{HO}_{2}$ detection because the alkoxy radicals formed in the reaction of $\mathrm{RO}_{2}$ radicals with $\mathrm{NO}$, may decompose and/or react with $\mathrm{O}_{2}$ sufficiently fast such that a detectable amount of $\mathrm{HO}_{2}$ radical is produced despite the short residence time $(<4 \mathrm{~ms})$ in the fluorescence cell. In order to reduce the impact of this interference, the concentration of $\mathrm{NO}$ in the $\mathrm{HO}_{2}$ detection cell was reduced to $\sim 2.5 \times 10^{13}$ molecule $\mathrm{cm}^{-3}$ in the experiments in this work. However, as discussed in detail in the ESI, $\dagger$ the modelled $\mathrm{HO}_{2}$ still differs substantially by up to a factor 10 from the measured $\mathrm{HO}_{2}$ radical concentrations, and at this time we are unable to ascertain whether this is due to missing chemistry in the model, remaining interference in the measurement, or a combination thereof. The analysis in this work will thus consider two limiting cases, one with the modelled $\mathrm{HO}_{2}$ concentration constrained to the measurement, and the other with the modelled $\mathrm{HO}_{2}$ unconstrained.

For the measurement of $\mathrm{RO}_{2}$ radicals using the ROxLIF system, these $\mathrm{RO}_{2}$ are first converted into alkoxy radicals in a converter $(\sim 25 \mathrm{hPa})$ by reactions with NO. Subsequent chemistry of these RO radicals leads to formation of $\mathrm{HO}_{2}$ radicals, which are sampled in the fluorescence cell $(\sim 4 \mathrm{hPa})$ downstream of the converter and are detected by $\mathrm{OH}$ fluorescence described above. The conversion efficiency through the ROxLIF system is calibrated using a reference $\mathrm{RO}_{2}\left(\mathrm{CH}_{3} \mathrm{OO}\right)$. The final signal also includes the contribution from $\mathrm{HO}_{2}$ radicals present in the air sampled from the chamber, and the $\mathrm{RO}_{2}$ concentration is derived by subtracting this contribution from the ROxLIF measurement based on the $\mathrm{HO}_{2}$ LIF measurement described higher. A recent paper by Novelli et $a l .{ }^{49}$ highlights how the LIF technique is likely to be blind to specific nitrated $\mathrm{RO}_{2}$ radicals due to the necessity of an $\mathrm{OH}$ or an $\mathrm{HO}_{2}$ radical to be formed for an $\mathrm{RO}_{2}$ radical to be detected. Specifically, it was found that the LIF technique cannot measure nitrated $\mathrm{RO}_{2}$ radicals formed from cis-2butene and 2,3-dimethyl-2-butene, as the corresponding alkoxy radicals decompose to $\mathrm{NO}_{2}$ instead of forming $\mathrm{HO}_{x}$ radicals. Similarly, the theoretical rate predictions for isoprene alkoxy radical reactions by the SAR described in that paper indicate that many of the nitrate- $\mathrm{RO}_{2}$ radicals from isoprene would not form $\mathrm{HO}_{2}$, and thus would not be detectable by the ROxLIF system. In this work, we estimate the conversion efficiencies of the dominant $\mathrm{RO}_{2}$ to detectable $\mathrm{OH}$ by explicit modelling of the converter and fluorescence cell chemistry (see ESI $\dagger$ ).

Measurements of isoprene (Fig. S11, ESI $\dagger$ ), as well as the sum of methyl vinyl ketone (MVK) and methacrolein (MACR) were performed by VOCUS PTR-MS (Tofwerk AG and Aerodyne Research Inc.). The VOCUS isoprene concentration profiles were calibrated against the change in $\mathrm{kOH}$ and $\mathrm{kNO}_{3}$ (total $\mathrm{OH}$ and $\mathrm{NO}_{3}$ reactivity measurements as shown for these experiments in Dewald et al. ${ }^{46}$ ) at the time of injection, to correct for any dependence of the VOCUS signal on relative humidity. Our kinetic model (see below) finds MVK and MACR to be present in similar concentrations. Therefore, we convert the signal strength measured by the VOCUS to the summed concentration of MVK + MACR by applying the mean of their respective instrumental sensitivities. $\mathrm{NO}_{3}$ concentrations (Fig. S11, ESI $\dagger$ ) were measured by a custom-built cavity ring down spectroscopy instrument as described in Dewald et al. ${ }^{46}$

\section{Theoretical results on the initial $\mathrm{NO}_{3}$ and $\mathrm{O}_{2}$ addition on isoprene}

The site- and stereo-specific $\mathrm{NO}_{3}$ and $\mathrm{O}_{2}$ addition chemical scheme for isoprene is reminiscent of the $\mathrm{LIM}^{12,13}$ mechanism for isoprene $+\mathrm{OH}$, i.e. both $\mathrm{OH}$ and $\mathrm{NO}_{3}$ addition leads to allylresonance stabilized alkyl radicals, which can reversibly add $\mathrm{O}_{2}$ on several radical sites forming distinct $\mathrm{RO}_{2}$ radicals. Such schemes for isoprene $+\mathrm{OH}$ are already implemented in the Master Chemical Mechanism, MCMv3.3.1, ${ }^{36}$ and in the recent isoprene mechanism described by Wennberg et al. ${ }^{4}$ Fig. 2 depicts the scheme for the dominant $\mathrm{NO}_{3}$ radical addition channel on carbon C1 in isoprene, which constitutes ${ }^{4} 87 \%$ of the reaction flux. The ESI $†$ has the corresponding schemes for addition on carbon $\mathrm{C} 4$, with a contribution ${ }^{4}$ of $13 \%$, and on the inner carbons $\mathrm{C} 2$ and $\mathrm{C} 3$, which have only a minor contribution and are neglected here. The addition reaction is exothermic by $\sim 32 \mathrm{kcal} \mathrm{mol}^{-1}$ for the formation of resonance-stabilized alkyl radicals. The redissociation of $\mathrm{NO}_{3}$-isoprene adducts to the reactants is negligible in our reaction conditions. Stereoisomerisation of the cis- and trans-alkyl radicals at thermal energies is slow compared to $\mathrm{O}_{2}$ addition and has no significant influence. Theoretical work by Peeters et al. ${ }^{12,13}$ and Dibble ${ }^{69}$ showed however that the internal rotation is fast at the internal energies available through the addition of the radical oxidant. As discussed in more detail in the ESI, $\dagger$ we adopt an initial distribution of $1: 1$ for cis:trans $1-\mathrm{NO}_{3}$-isoprenyl, and $7: 3$ for cis: trans $4-\mathrm{NO}_{3}$-isoprenyl, based on these studies.

Similar to $\mathrm{OH}$-adducts of isoprene, the $\mathrm{O}_{2}$ addition is not overly exothermic, $\leq 20 \mathrm{kcal} \mathrm{mol}^{-1}$, and the $\mathrm{O}_{2}$ addition is reversible, allowing re-equilibration of the $\mathrm{RO}_{2}$ isomers by repetitive $\mathrm{O}_{2}$ elimination/addition events. This re-equilibration occurs in competition with unimolecular and bimolecular loss processes of the $\mathrm{RO}_{2}$ radicals, as discussed in a later section. An a priori characterization of the $\mathrm{O}_{2}$ addition and elimination reaction rates at sufficient accuracy for a kinetic model is computationally very expensive due to the (nearly) barrierless addition process, ${ }^{12}$ and the complexity in the quantum chemical description of the spin states of the many unpaired electrons. At this time, we therefore choose not to predict rate coefficients for these reactions directly. Instead, we adopt $\mathrm{O}_{2}$ 


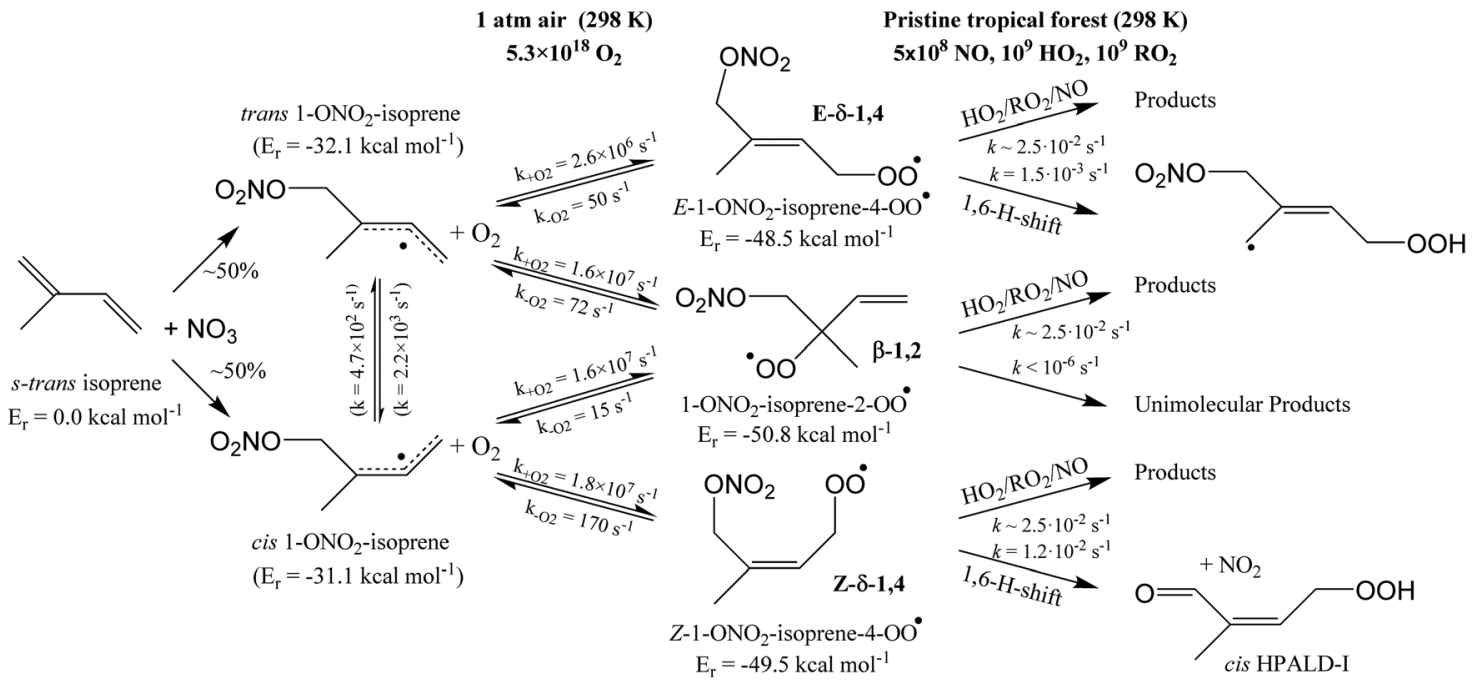

Fig. 2 Reaction scheme for the site-specific addition of $\mathrm{NO}_{3}$ on $\mathrm{C} 1$ of isoprene, and the subsequent stereo-specific addition of $\mathrm{O}_{2}$. The $\mathrm{ESI} \dagger$ includes schemes for $\mathrm{NO}_{3}$-addition on carbons $\mathrm{C} 2, \mathrm{C} 3$ and C4. Co-reactant concentrations are taken as in Peeters et al. ${ }^{12}$

addition rate coefficients as for the $\mathrm{OH}$-isoprenyl $+\mathrm{O}_{2}$ reaction in the MCM v3.3.1 as based on the available literature data $^{12,13,18,36}$ and evaluated by Novelli et $a .^{14}$ The detailed analysis of Novelli et al. ${ }^{14}$ showed that a suitable ratio of formation to destruction rates is critical for a correct product distribution. The rate coefficients for $\mathrm{O}_{2}$ elimination from $\mathrm{NO}_{3}$-isoprene- $\mathrm{O}_{2}$ radicals are then obtained from the forward $\mathrm{O}_{2}$-addition reaction rates and theory-derived equilibrium constants, similar to the approach by Peeters et al. ${ }^{13}$ More details, the temperature-dependent rate coefficients, and the equilibrium constants are provided in the ESI. $\dagger$

\section{Theoretical results on nitrate- $\mathrm{RO}_{2}$}

\subsection{Elementary reactions}

Table 1 summarizes the rate coefficients obtained for the unimolecular reactions of $\mathrm{RO}_{2}$ radicals formed in the isoprene $+\mathrm{NO}_{3}+\mathrm{O}_{2}$ reaction. The theoretical results are compared against SAR predictions in the ESI. $\dagger$

1,6-H-Migration of the $\alpha$-nitrooxy $\mathrm{H}$-atom $\left(-\mathrm{CH}_{2} \mathrm{ONO}_{2}\right)$ is the most favorable transition state, followed by migration of the methyl H-atoms. 1,4-H-Migrations are never competitive, nor are $\mathrm{H}$-migrations between trans-substituents of the double bond. $\mathrm{HO}_{2}$ elimination with either the $\alpha$-nitrooxy or the methyl $\mathrm{H}$-atom was only examined for a single compound $\left(1-\mathrm{ONO}_{2}-\right.$ isoprene-2-OO•) but as expected this reaction has sizable barriers exceeding $26 \mathrm{kcal} \mathrm{mol}^{-1}$, in agreement with earlier work, ${ }^{70-73}$ and can be neglected. Ring closure reactions should be divided into three categories: formation of 5-membered peroxide rings with an endo-cyclic alkyl radical site, formation of 5-membered rings with an exo-cyclic radical site, and formation of 6-membered rings (here always with an endo-cyclic radical site). Most nitrate- $\mathrm{RO}_{2}$ discussed here only have access to the first category, which typically has higher barriers $\geq 25 \mathrm{kcal} \mathrm{mol}^{-1}$, making them non-competitive. The barriers are a direct result of the ring strain in the TS, where the double bond is still intact and reaching the outer alkenic carbon with a 5-membered ring structure induces significant ring strain. If, on the other hand, the ring closure occurs on the inner carbon of the double bond, as e.g. in 2- $\mathrm{ONO}_{2}$-isoprene-1-OO ${ }^{\bullet}$ or 3- $\mathrm{ONO}_{2}$-isoprene-4-OO formed in the minor isoprene $+\mathrm{NO}_{3}$ addition channels, the ring strain in the TS is significantly less and ring closure TS energies of $\sim 13-15 \mathrm{kcal} \mathrm{mol}^{-1}$ are found even for 5-membered rings. For 6-membered ring closure, here possible only in the latter two nitrate- $\mathrm{RO}_{2}$, the ring strain is significantly reduced despite the endo-cyclic double bond in the TS, and attack on the outer alkenic carbon also has low barriers, $14-16 \mathrm{kcal} \mathrm{mol}^{-1}$.

Compared to the $\mathrm{OH}$-substituted $\mathrm{RO}_{2}$ radicals formed in isoprene $+\mathrm{OH}$, the unimolecular rate coefficients for nitrate$\mathrm{RO}_{2}$ are generally slower. For example, the $\mathrm{NO}_{2}$-forming $1,6-\mathrm{H}-$ migration in $Z$-1-ONO ${ }_{2}$-isoprene-4-OO forming HPALD has a calculated rate coefficient $k(298 \mathrm{~K})=1.9 \times 10^{-2} \mathrm{~s}^{-1}$, whereas the analogous $\mathrm{OH}$-regenerating $\mathrm{H}$-shift in $\mathrm{Z}$-1-OH-isoprene-4-OO has a predicted rate of $\sim 0.5 \mathrm{~s}^{-1},{ }^{12-14,74}$ a factor of 25 faster. The few $\mathrm{RO}_{2}$ for which faster reactions are accessible, such as ring closure in 2- and 3- $\mathrm{ONO}_{2}$-isoprene- $\mathrm{RO}_{2}$, are formed only in minor to negligible $\mathrm{NO}_{3}$ addition channels on isoprene. Unimolecular reactions of nitrate- $\mathrm{RO}_{2}$ will thus be less important than for $\mathrm{OH}-\mathrm{RO}_{2}$ under atmospheric conditions, and become negligible even for only moderately elevated $\mathrm{NO}_{x}, \mathrm{HO}_{2}$, and $\mathrm{RO}_{2}$ concentrations. In the current experiments, the $\mathrm{OH}$ reaction still contributes for $\sim 10 \%$ of the isoprene loss, and given the expected small yields through unimolecular channels in the $\mathrm{NO}_{3}$-isoprene system, and the possibility of formation of isobaric products in other channels, products measurements such as for HPALD can likely not be used to verify a product yield prediction.

\subsection{Equilibrium populations and bulk rate coefficients}

As already discussed in detail in the literature on $\mathrm{OH}$-initiated oxidation of isoprene and aromatic compounds, ${ }^{12,13,75}$ a key 
Table 1 Theoretical rate predictions for nitrated alkylperoxy radicals derived from isoprene $+\mathrm{NO}_{3}+\mathrm{O}_{2}$, at the CCSD(T)/aug-cc-pVTZ//M06-2X/ aug-cc-pVTZ with MC-TST level of theory. Indicated are the ZPE-corrected barrier height $\left(E_{\mathrm{b}}, \mathrm{kcal} \mathrm{mol}^{-1}\right)$, the $298 \mathrm{~K} \mathrm{rate}$ coefficient $\left(k(298 \mathrm{~K}), \mathrm{s}^{-1}\right)$, and the parameters for a Kooij expression $k(T)=A \times(T / K)^{n} \times \exp \left(-E_{\mathrm{a}} / T\right)\left(A\right.$ in s $^{-1}, E_{\mathrm{a}}$ in $\left.\mathrm{K}\right)$. The rate coefficients are the rate of product formation across all equivalent $\mathrm{H}$-atoms

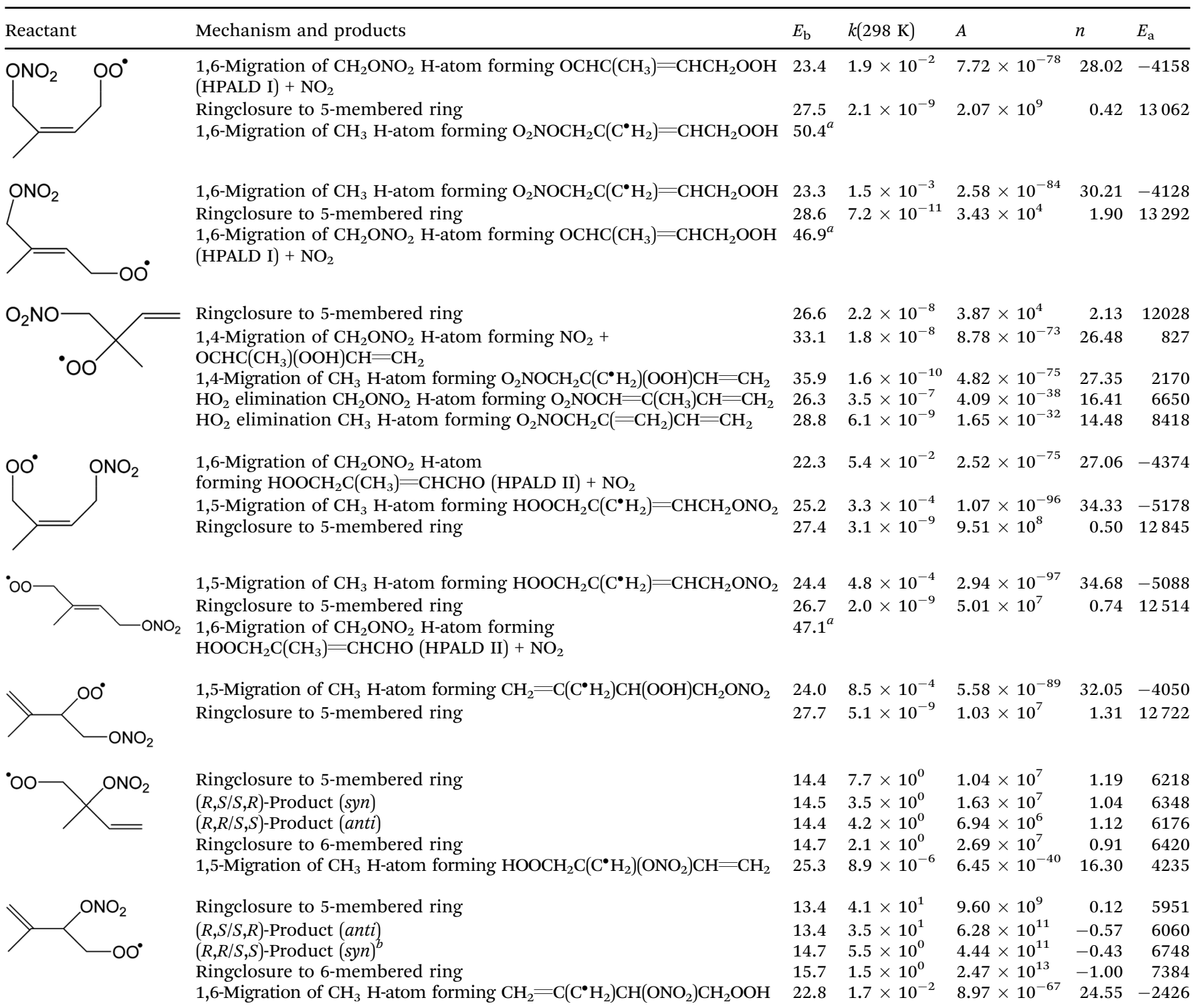

${ }^{a}$ Energies at the M06-2X/aug-cc-pVTZ level of theory. Given the barrier height, CCSD(T) and rate calculations were not done. ${ }^{b}$ Less favorable as the adjacent syn-positioned $-\mathrm{CH}_{3}$ and $-\mathrm{ONO}_{2}$ groups induce more geometric hindrance.

feature of the atmospheric chemistry of allylic radicals is the reversibility of the $\mathrm{O}_{2}$ addition. For isoprene in particular this means that the $\mathrm{RO}_{2}$ radicals can interconvert by redissociation and $\mathrm{O}_{2}$ addition, in competition with unimolecular and bimolecular $\mathrm{RO}_{2}$ loss processes. In this context, three $\mathrm{RO}_{2}$ populations are of interest. The first is the nascent $\mathrm{RO}_{2}$ distribution formed directly from the isoprene $+\mathrm{NO}_{3}+\mathrm{O}_{2}$ reaction sequence. This distribution governs the product distribution at high rates of $\mathrm{RO}_{2}$ loss, e.g. in experiments with very high co-reactant concentrations. The second is the equilibrium $\mathrm{RO}_{2}$ population, established when the loss processes are negligible compared to re-equilibration by $\mathrm{O}_{2}$ elimination/addition. Finally, there is the instantaneous $\mathrm{RO}_{2}$ distribution, intermediate between the above two limiting distributions and determined by the competition between $\mathrm{RO}_{2}$ formation, reactive loss, and re-equilibration as governed by the specific reaction conditions; this distribution can be time-dependent if the environment (e.g. co-reactant concentrations) changes at a time scale comparable to the rate of population change.

These distributions are derived and discussed in more detail the ESI. $\dagger$ Briefly: the nascent $\mathrm{RO}_{2}$ distribution can in principle be derived from measured product ratios at high co-reactant concentrations (e.g. NO), where the re-equilibration is overwhelmed, but no sufficiently detailed data are available. In this work, we estimate the nascent distribution by assuming a cis : trans ratio for $\mathrm{NO}_{3}$-isoprenyl radicals as calculated by Peeters et $a .^{12,13}$ for the $\mathrm{HO}$-isoprenyl radicals. Reaction rates of the subsequent $\mathrm{O}_{2}$ 
addition are adopted from the MCM v3.3.1 for OH-isoprenyl + $\mathrm{O}_{2},{ }^{36}$ which are calibrated against the experimental data on $\mathrm{RO}_{2}$ decomposition from Teng et al. ${ }^{18}$ and evaluated in Novelli et al. ${ }^{14}$ Combined, this yields the nascent $\mathrm{RO}_{2}$ population (see ESI $\dagger$ ). The equilibrium $\mathrm{RO}_{2}$ populations can be predicted directly from the theoretical data. Strictly speaking, this distribution cannot be reached experimentally even in dilute conditions due to (slight) perturbations of the population due to unimolecular and bimolecular reactions. For the $\mathrm{OH}$-initiated oxidation, it was found that in atmospheric conditions the instantaneous isoprene- $\mathrm{RO}_{2}$ concentration is intermediate between the nascent and equilibrium populations, and that kinetic models need to include all chemical pathways. ${ }^{12-14}$ For nitrated $\mathrm{RO}_{2}$, unimolecular loss is slower and the instantaneous population is expected to be close to equilibrium distributions under atmospheric conditions, and under the conditions in our experiments.

To aid in the characterization of the nitrate- $\mathrm{RO}_{2}$, we provide the theoretically derived temperature-dependent equilibrium contributions to the population in Table 2, and shown in Fig. 3 (see ESI $\dagger$ for more populations). At temperatures below $450 \mathrm{~K}$, the population is dominated by $1-\mathrm{ONO}_{2}$-isoprene-2-OO ${ }^{\bullet}$ isomers, the most stable of the $\mathrm{RO}_{2}$ isomers formed after the dominant $\mathrm{NO}_{3}$ addition on isoprene. The 4-ONO 2 -isoprene $\mathrm{RO}_{2}$ are not dominated by a single $\mathrm{RO}_{2}$ isomer. The distribution of the $\mathrm{RO}_{2}$ has its impact on the phenomenological rate coefficient, i.e. the bulk rate coefficient for product formation from the total pool of $\mathrm{RO}_{2}$ isomers. For unimolecular reactions, these differ from the elementary reaction rates as the re-equilibration allows access to all reaction channels independent of the starting $\mathrm{RO}_{2}$ isomer, and because the effective

Table 2 Theoretical predictions for the equilibrium population for nitrated alkylperoxy radicals derived from isoprene $+\mathrm{NO}_{3}+\mathrm{O}_{2}$, at the CCSD(T)/aug-cc-pVTZ//M06-2X/aug-cc-pVTZ with MC-TST level of theory. Indicated are the relative energies $\left(\mathrm{kcal} \mathrm{mol}^{-1}\right)$ of the lowest conformer, the $298 \mathrm{~K}$ population fraction $f(298 \mathrm{~K})$, and the parameters for a Kooij expression $f(T)=F \times(T / K)^{n} \times \exp \left(-E_{\mathrm{a}} / T\right)\left(E_{\mathrm{a}}\right.$ in $\left.\mathrm{K}\right)$. This Boltzmann distribution is attained only in the absence of loss processes, but is closely adhered to under the conditions of our experiments (see ESI)

\begin{tabular}{|c|c|c|c|c|c|}
\hline Reactant & $E_{\text {rel }}$ & $f(298 \mathrm{~K})$ & $F$ & $n$ & $E_{\mathrm{a}}$ \\
\hline $\mathrm{ONO}_{2}$ & & & & & \\
\hline & 1.3 & 0.08 & $2.59 \times 10^{2}$ & -0.96 & 788 \\
\hline & 2.3 & 0.18 & $6.55 \times 10^{9}$ & -3.18 & 1851 \\
\hline & 0.0 & 0.74 & $4.02 \times 10^{5}$ & -2.10 & 365 \\
\hline & 0.3 & 0.20 & $1.03 \times 10^{-3}$ & 0.90 & -34 \\
\hline & 0.8 & 0.40 & $2.72 \times 10^{2}$ & -0.92 & 373 \\
\hline & 0.0 & 0.40 & $5.44 \times 10$ & -0.50 & -67 \\
\hline
\end{tabular}
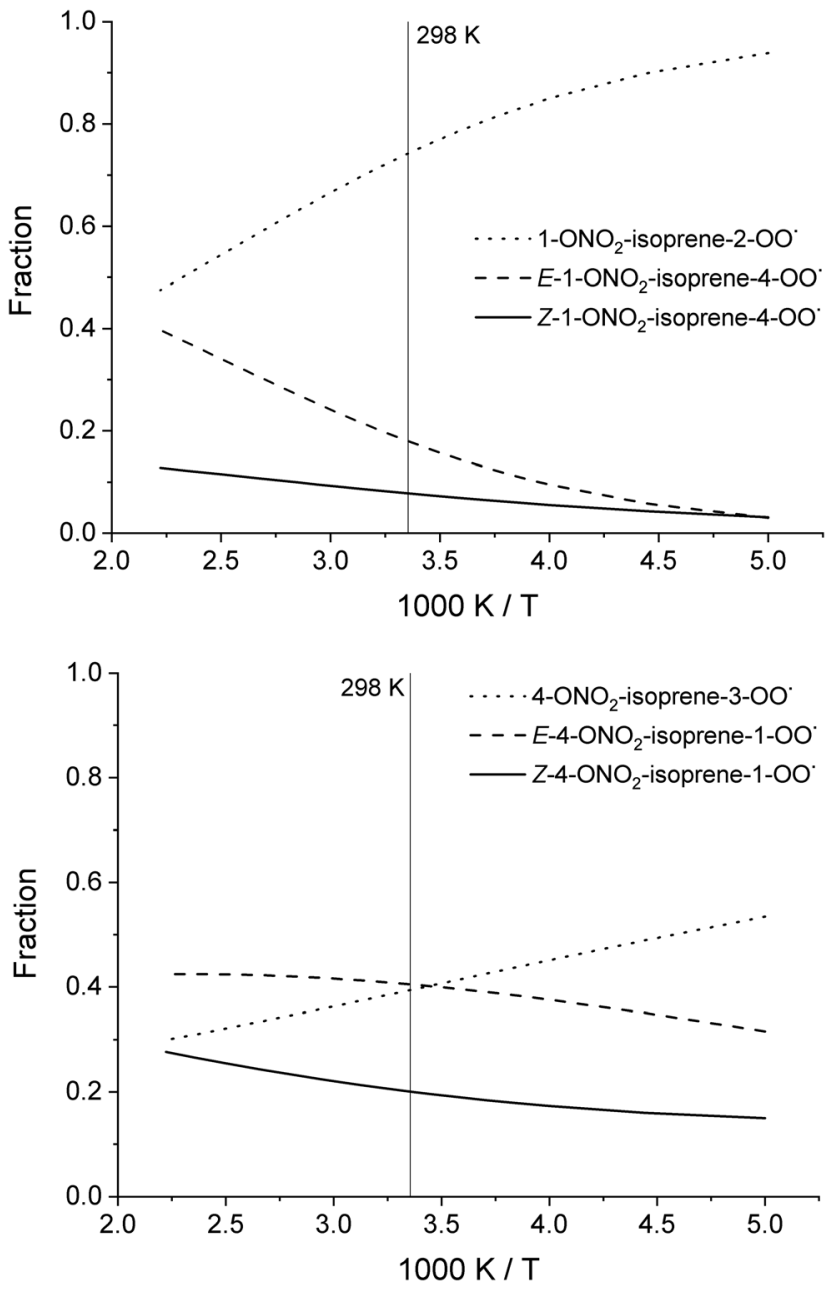

Fig. 3 Temperature-dependent equilibrium population contribution for the individual $\mathrm{RO}_{2}$ isomers formed after $\mathrm{NO}_{3}$ addition to $\mathrm{C} 1$ (top) or $\mathrm{C} 4$ (bottom) of isoprene.

reactant concentration for any particular channel is only a fraction of the total $\mathrm{RO}_{2}$ concentration. In Table 3 , we provide the bulk rate coefficients for the nitrated $\mathrm{RO}_{2}$ in an equilibrium population; the experimental bulk rate coefficient can differ as the $\mathrm{RO}_{2}$ distribution and re-equilibration will be different.

\section{Theoretical results on nitrate-RO}

Table 4 lists the predicted rate coefficients for the most important reaction pathways of the alkoxy radicals formed from the primary nitrate- $\mathrm{RO}_{2}$ from isoprene $+\mathrm{NO}_{3}$. The theoretical results are compared against SAR predictions in the ESI. $\dagger$ Decomposition reactions eliminating the nitrate-bearing moiety, and $\mathrm{H}$-migration of the $\gamma-\mathrm{ONO}_{2}$ hydrogen atoms are among the most important channels. These reactions lead to fragmentation of the nitrate moiety in the product $\gamma-\mathrm{ONO}_{2}$ alkyl radicals, forming $\mathrm{NO}_{2}$ and aborting the organic radical oxidation chain. In two cases, migration of a methyl $\mathrm{H}$-atom is among the faster reactions, though these $\mathrm{H}$-shifts are typically slower than migration of the $\gamma-\mathrm{ONO}_{2}$ 
Table 3 Theoretical predictions for bulk rate coefficients of the main unimolecular loss channels for nitrated alkylperoxy radicals derived from isoprene $+\mathrm{NO}_{3}+\mathrm{O}_{2}$, in their equilibrium concentrations, at the CCSD(T)/aug-cc-pVTZ//M06-2X/aug-cc-pVTZ with MC-TST level of theory. Indicated are the ZPE-corrected barrier height $\left(\mathrm{kcal} \mathrm{mol}^{-1}\right)$, the $298 \mathrm{~K}$ rate coefficient $\left(k(298 \mathrm{~K}), \mathrm{s}^{-1}\right)$, and the parameters for a Kooij $\operatorname{expression~} k(T)=A \times(T / K)^{n} \times \exp \left(-E_{\mathrm{a}} /\right.$ $T)\left(A\right.$ in $\mathrm{s}^{-1}, E_{\mathrm{a}}$ in $\left.\mathrm{K}\right)$. The rate coefficients are the rate of product formation across all equivalent $\mathrm{H}$-atoms

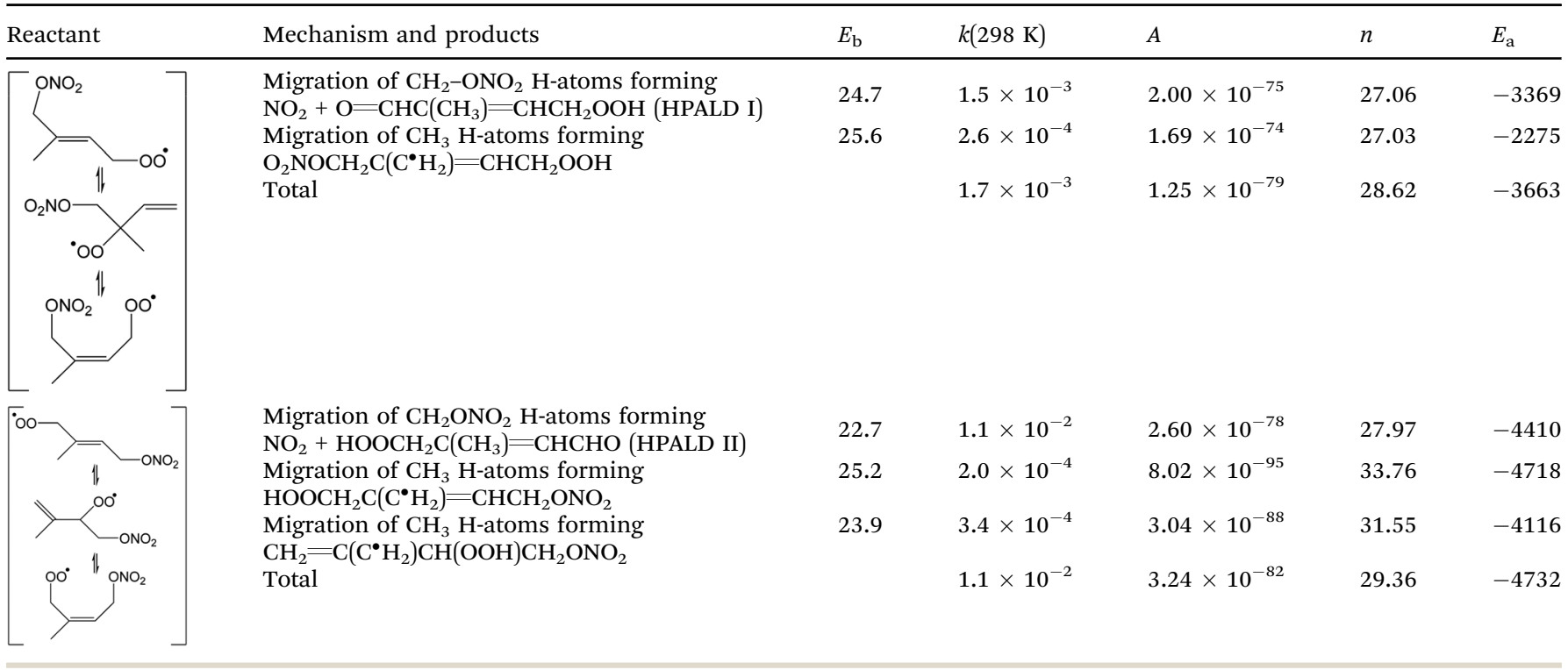

hydrogen atoms. All the above nitrate-RO reactions are typically faster than the reaction of the nitrate-RO with $\mathrm{O}_{2}$, forming a carbonyl and $\mathrm{HO}_{2}$, thus often forgoing chain termination forming $\mathrm{HO}_{2}$ by formation of $\mathrm{NO}_{2}$ instead. It is important to note that reactions of the nitrate- $\mathrm{RO}$ are typically slower than the analogous reactions of hydroxylated alkoxy radicals formed in the $\mathrm{OH}$ initiated oxidation of isoprene, enabling alternative reactions to become competitive. In particular, the adjacent double bond allows for epoxidation reactions (see Table 4), leading to the formation of nitrated epoxy alkyl radicals, which are isoenergetic with the parent nitrate-RO radicals within a few $\mathrm{kcal} \mathrm{mol}^{-1}$. Epoxidation reactions in unsaturated compounds has been studied before, mainly in the atmospheric oxidation of aromatic compounds, ${ }^{75,76}$ and are found to be fast and reversible (see below). The competitive epoxidation has important ramifications for the predicted product distribution. For example, the main fate of $1-\mathrm{NO}_{3}$-isoprene-2-O $\mathrm{O}^{\bullet}$ is now predicted to be formation of the epoxide, hampering formation of methyl vinyl ketone (MVK), a well-known product of atmospheric isoprene oxidation. This epoxidation channel would also preclude MVK formation as proposed by Wennberg et $a .^{4}$ in the reaction of $1-\mathrm{NO}_{3}$-isoprene2-OO ${ }^{\bullet}$ with $\mathrm{HO}_{2}$. As the epoxidation is reversible, the final product formation from the nitrate-RO can only be assessed through an explicit chemical mechanism. Contrary to the ring closure reaction in nitrate- $\mathrm{RO}_{2}$, ring closure in the isoprene-derived nitrate-RO radicals across longer spans than epoxidation is not competitive.

\section{Theoretical results for epoxy radicals}

Chemical schemes for epoxidation and subsequent chemistry are shown in Fig. 4. Due to the highly branching nature of the chemistry, not all pathways were theoretically characterized, but rely on SAR predictions instead. The theoretical predictions available are discussed below.

\subsection{Epoxy-alkyl radicals: ring breaking versus $\mathrm{O}_{2}$ addition}

The epoxy-alkyl radicals formed from the nitrate-RO have two reaction pathways available: ring opening back to the nitrate$\mathrm{RO}$, or addition of an $\mathrm{O}_{2}$ molecule, forming an epoxy-nitrate$\mathrm{RO}_{2}$. The epoxy-alkyl radicals have an interesting impact on the stereo-specificity of the reaction, where the $Z$ - and $E-1-\mathrm{NO}_{3}$ isoprene-4- $\mathrm{O}^{\bullet}$ radicals form the same alkyl-epoxy radical (Table 5 and $\mathrm{ESI} \dagger$ ). As the internal rotation of the epoxymoiety is comparable in rate or faster than the epoxy ring opening, ${ }^{21}$ this enables $Z / E$-stereo-isomerisation by reversible epoxidation; similar stereo-isomerisation has been reported earlier by Nguyen and Peeters ${ }^{21}$ for other unsaturated alkoxy radicals. A different type of stereo-chemistry is found for the 1- $\mathrm{NO}_{3}$-isoprene-2-O $\mathrm{O}^{\bullet}$ radical, which leads to two stereo-specific alkyl-epoxy radicals with distinct chemistry (Table 5 and Fig. 4). Similar stereo-specific considerations apply to the intermediates formed after $\mathrm{NO}_{3}$ addition on $\mathrm{C} 4$ of isoprene (see $\mathrm{ESI} \dagger$ ). As the epoxidation is essentially energy-neutral and the barriers for ring opening/closing are low, the ring opening is as fast as the epoxidation reaction, $k(298 \mathrm{~K}) \sim 10^{8} \mathrm{~s}^{-1}$, enabling fast interconversion between the nitrate-RO and the epoxy-alkyl radical (Tables 4 and 5). The ultimate fate of the nitrate-RO is then determined by the competition between $\mathrm{O}_{2}$ addition on the epoxy-alkyl radical, versus the dissociation or H-migration in the nitrate-RO. Recombination reactions of larger alkyl radicals with $\mathrm{O}_{2}$ are comparatively fast, $k(298 \mathrm{~K}) \sim 5.6 \times$ $10^{-13}$ to $1.7 \times 10^{-11} \mathrm{~cm}^{3}$ molecule $\mathrm{s}^{-1} \cdot{ }^{-17-80}$ Contrary to the nitrate- $\mathrm{RO}_{2}$ discussed above, the product epoxy- $\mathrm{RO}_{2}$ are not expected to redissociate as the parent epoxy-alkyl radicals are not resonance stabilized. Adopting a value for $\mathrm{O}_{2}$ addition of 
Table 4 Theoretical rate predictions for nitrate-RO radicals derived from isoprene $+\mathrm{NO}_{3}$, at the CCSD(T)/aug-cc-pVTZ//M06-2X/aug-cc-pVTZ with MC-TST level of theory. Indicated are the ZPE-corrected barrier height $\left(E_{\mathrm{b}}, \mathrm{kcal} \mathrm{mol}^{-1}\right)$, the $298 \mathrm{~K}$ rate coefficient $\left(k(298 \mathrm{~K}), \mathrm{s}^{-1}\right)$, and the parameters for a Kooij expression $k(T)=A \times(T / K)^{n} \times \exp \left(-E_{a} / T\right)\left(A\right.$ in s${ }^{-1}, E_{a}$ in $\left.K\right)$. Reaction channels anticipated by SARs to be negligible are omitted

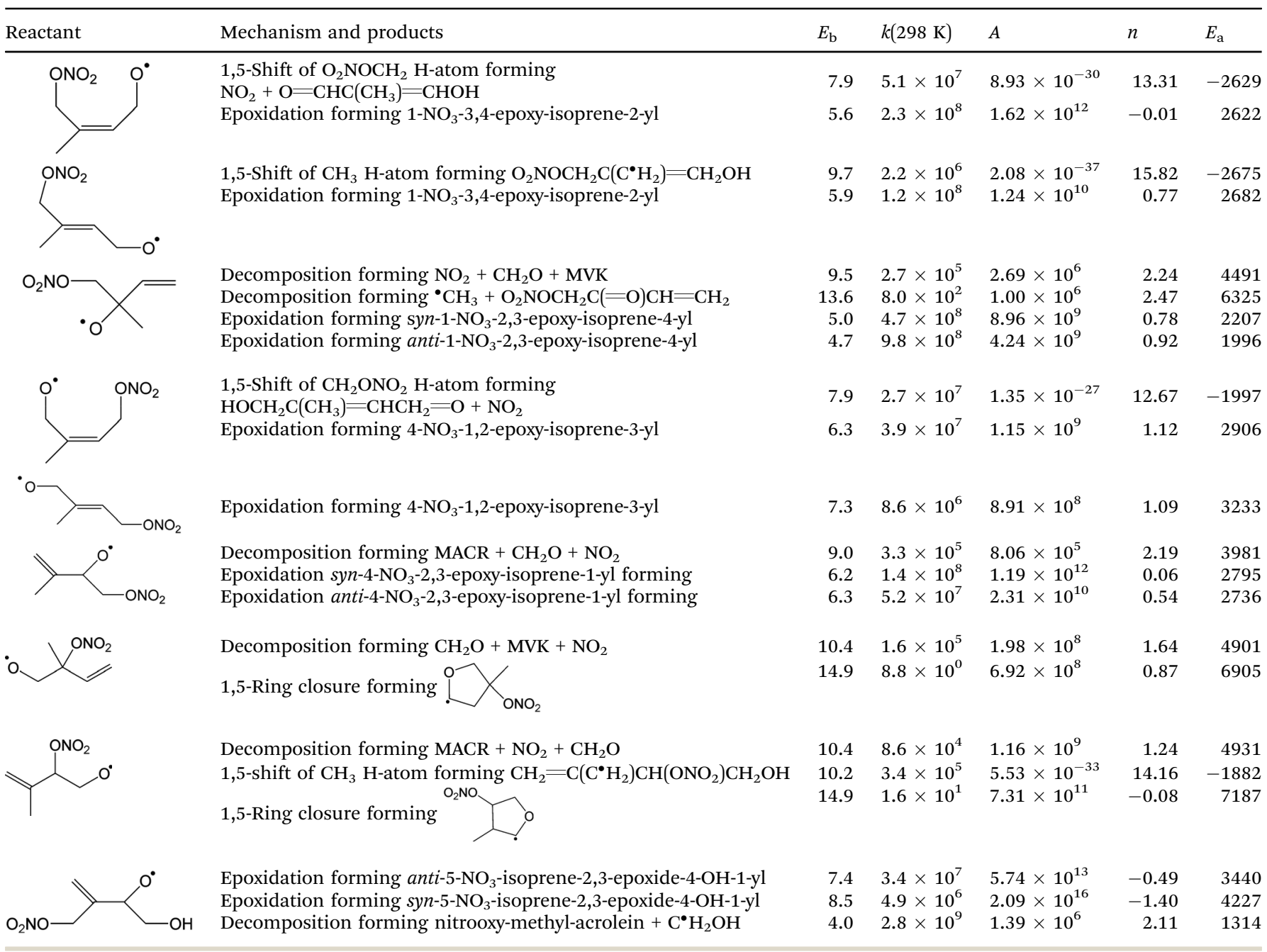

$k(298 \mathrm{~K})=7.5 \times 10^{-12} \mathrm{~cm}^{3}$ molecule $\mathrm{s}^{-1}$ leads, under atmospheric conditions $\left(0.2\right.$ atm $\left.\mathrm{O}_{2}\right)$, to a pseudo-first order rate coefficient of $k(298 \mathrm{~K}) \approx 5 \times 10^{7} \mathrm{~s}^{-1}$. For many of the nitrateRO radicals formed from isoprene, the main fate is then formation of an epoxy-nitrate- $\mathrm{RO}_{2}$ radical.

The rate of opening of the epoxy-ring is of the same order of magnitude as the $\mathrm{O}_{2}$ addition in most cases, such that bulk rate coefficients across the alkoxy/epoxy system are not valid. Still, for atmospheric modeling purposes, some model simplification remains possible. Between $250-350 \mathrm{~K}$ and 0.2 to $1 \mathrm{~atm}$ air, 1- $\mathrm{NO}_{3}$-isoprene-2-O $\mathrm{O}^{\bullet}$ radicals convert to $68 \pm 2 \%$ anti-1- $\mathrm{NO}_{3}-2,3-$ epoxy-isoprene-4-OO ${ }^{\bullet}$, with the remainder forming $s y n-1-\mathrm{NO}_{3}$ 2,3-epoxy-isoprene-4-OO ${ }^{\bullet}$, while direct alkoxy radical reaction with $\mathrm{O}_{2}$ or alkoxy dissociation to $\mathrm{NO}_{2}$ constitute less than $0.1 \%$. For $4-\mathrm{NO}_{3}$-isoprene-3-O ${ }^{\bullet}$ radicals we find $26 \pm 3 \%$ anti-4- $\mathrm{NO}_{3}$ 2,3-epoxy-isoprene-1-OO ${ }^{\bullet}$, with the remainder forming syn-4$\mathrm{NO}_{3}$-2,3-epoxy-isoprene-1-OO ${ }^{\bullet}$, while direct reactions with $\mathrm{O}_{2}$ and dissociation to $\mathrm{NO}_{2}$ constitute less than $0.4 \%$. For the 1- $\mathrm{NO}_{3}$-2,3-epoxy-4-OH-isoprene-5-yl and 5- $\mathrm{NO}_{3}-4-\mathrm{OH}$-isoprene$3-\mathrm{O}^{\bullet}$ radicals (Fig. 4) the near-exclusive fate is formation of nitrated MACR $+\mathrm{HCHO}+\mathrm{HO}_{2}$, owing to the fast decomposition in the alkoxy radical. For the other nitrate- $\mathrm{RO}_{2}$, the unimolecular reactions are more competitive against $\mathrm{O}_{2}$ addition in the epoxyalkyl radical, and the final product distribution shows stronger temperature- and pressure dependencies that are not readily reduced to a single value.

It is interesting to note that unsaturated, hydroxylated RO radicals are less likely to form epoxy- $\mathrm{RO}_{2}$ radicals than unsaturated nitrate-RO radicals. Compared to a nitrate group, an -OH substituent tends to lead to faster isomerisation and decomposition reactions, ${ }^{38,49,60}$ which often dominate over the $\mathrm{O}_{2}$ addition in the epoxy-alkyl intermediate. Examples include the fast elimination of $\mathrm{C}^{\bullet} \mathrm{H}_{2} \mathrm{OH}$ radicals from the $\beta$-OH-alkoxy radical in Fig. 4, or the fast $\mathrm{H}$-migration in the $\delta$-OH-alkoxy radical studied by Nguyen and Peeters. ${ }^{21}$ This suggests that formation of epoxides could be more prevalent in nighttime $\mathrm{NO}_{3}$-initiated oxidation of terpenoids, compared to the $\mathrm{OH}$-initiated oxidation dominant during daytime, which may have repercussions for aerosol formation and growth by reactive uptake. In judging the impact of epoxidation, one should also consider that 


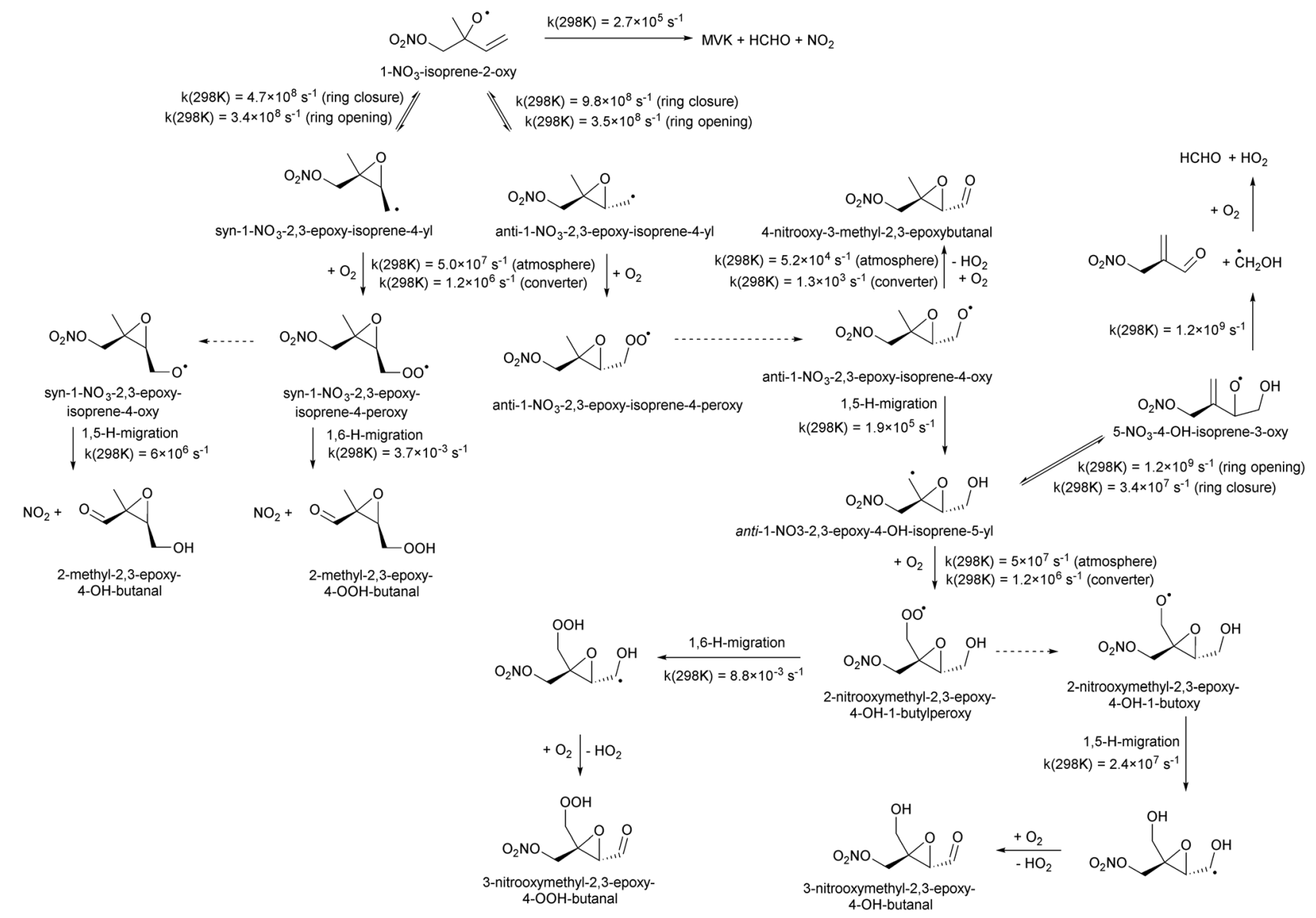

Fig. 4 Oxidation scheme showing the dominant pathways for 1- $\mathrm{NO}_{3}$-isoprene-2-O radicals formed in the $\mathrm{NO}_{3}$-initiated oxidation of isoprene. The dotted arrows indicates alkoxy radical formation in the reaction of $\mathrm{RO}_{2}$ with $\mathrm{NO}, \mathrm{NO}_{3}, \mathrm{HO}_{2}$, or $\mathrm{R}^{\prime} \mathrm{O}_{2}$; these reactions are not depicted. In the high- $\mathrm{NO}$ low-pressure conditions of the converter, anti-stereoisomers will be detectable by partially forming $\mathrm{HO}_{2}$, while syn-isomers will eliminate $\mathrm{NO}_{2}$ and can not be detected by ROxLIF.

subsequent chemistry of the epoxy radicals formed could form $\beta$-epoxy-alkyl radicals that de-epoxidize, and thus reduce the yield of epoxidized products. Fig. 4 shows an example for 1- $\mathrm{NO}_{3}$-isoprene-2-O ${ }^{\bullet}$ radicals: about two thirds of this nitrate$\mathrm{RO}$ radical forms anti-substituted epoxy- $\mathrm{RO}_{2}$, but subsequent $\mathrm{H}$-migration in the product alkoxy radical allows for rapid de-epoxidation and fragmentation forming nitrated MACR + $\mathrm{HCHO}+\mathrm{HO}_{2}$ as the main product under oxidative conditions.

\subsection{H-Migration reactions in epoxidized nitrate- $\mathrm{RO}_{2}$ radicals}

Table 6 lists a set of calculations on epoxy-nitrate- $\mathrm{RO}_{2}$ radicals derived from isoprene. H-Migration of an aliphatic or an $\alpha$-ONO ${ }_{2}-\mathrm{H}$-atom across the epoxide functionality is an order of magnitude faster than the predictions by the SAR by Vereecken and Nozière for corresponding $\mathrm{H}$-migrations in non-cyclic $\mathrm{RO}_{2}$ radicals. This contrasts with the results for epoxidized alkoxy radicals by Novelli et al. ${ }^{49}$ who found little

Table 5 Theoretical rate predictions for ring opening in nitrate-epoxy-alkyl radicals derived from isoprene + NO 3 , at the CCSD(T)/aug-Cc-pVTZ//M06-

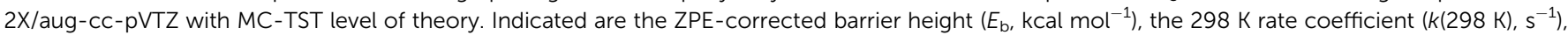
and the parameters for a Kooij expression $k(T)=A \times(T / K)^{n} \times \exp \left(-E_{a} / T\right)\left(A\right.$ in s${ }^{-1}, E_{a}$ in $\left.K\right)$. The rate of recombination with $\mathrm{O}_{2}$ molecules under atmospheric conditions is estimated at $k(298 \mathrm{~K}) \approx 5 \times 10^{7} \mathrm{~s}^{-1}$ (see text)

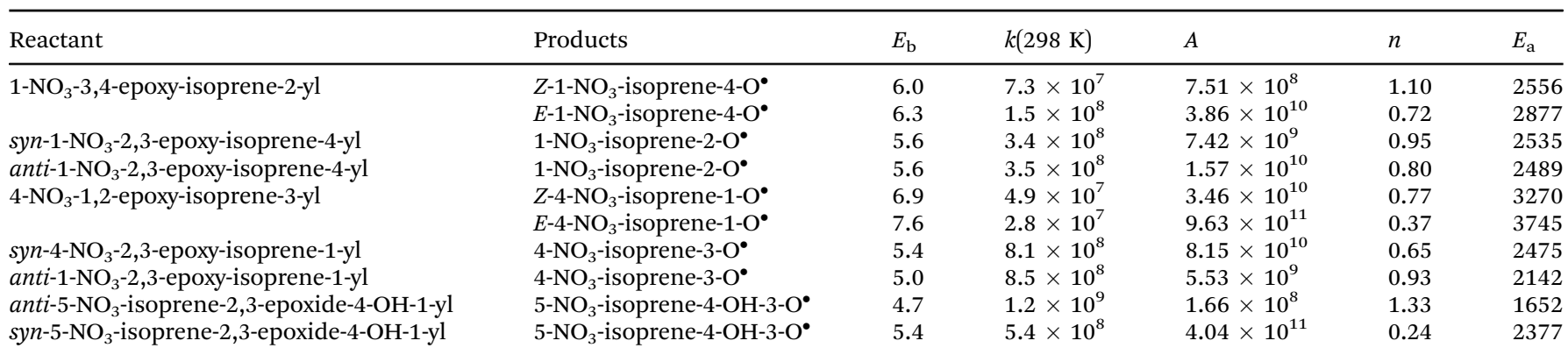


Table 6 Theoretical predictions for a series of epoxy-peroxy and epoxy-nitrate-peroxy radicals, at the CCSD(T)/aug-cc-pVTZ//M06-2X/aug-cc-pVTZ with MC-TST level of theory. Indicated are the ZPE-corrected barrier height $\left(E_{\mathrm{b}}, \mathrm{kcal} \mathrm{mol}^{-1}\right)$, the $298 \mathrm{~K}$ rate coefficient $\left(\mathrm{K}^{2}(298 \mathrm{~K}), \mathrm{s}^{-1}\right)$, and the parameters for a Kooij expression $k(T)=A \times(T / K)^{n} \times \exp \left(-E_{\mathrm{a}} / T\right)\left(A\right.$ in $\mathrm{s}^{-1}, E_{\mathrm{a}}$ in $\left.\mathrm{K}\right)$

\begin{tabular}{|c|c|c|c|c|c|c|c|}
\hline Reactant & Mechanism and products & Stereo $^{a}$ & $E_{\mathrm{b}}$ & $k(298 \mathrm{~K})$ & $A$ & $n$ & $E_{\mathrm{a}}$ \\
\hline & 1,6-H-shift of $\mathrm{O}_{2} \mathrm{NOCH}_{2} \mathrm{H}$-atom & & 24.0 & $3.7 \times 10^{-3}$ & $1.77 \times 10^{-83}$ & 30.09 & -4035 \\
\hline & 1,6-H-shift of $\mathrm{CH}_{3}$ & & 24.8 & $1.2 \times 10^{-4}$ & $1.71 \times 10^{-96}$ & 34.52 & -4434 \\
\hline & 1,5-H-shift of $\alpha$-epoxy $\mathrm{H}$-atom & $\begin{array}{l}(R, S) /(S, R) \\
(R, R) /(S, S) \\
\text { Geom. ave. }\end{array}$ & $\begin{array}{l}24.5 \\
25.2\end{array}$ & $\begin{array}{l}3.6 \times 10^{-4} \\
9.7 \times 10^{-5} \\
1.9 \times 10^{-4}\end{array}$ & $\begin{array}{l}1.35 \times 10^{-93} \\
7.30 \times 10^{-98} \\
9.92 \times 10^{-96}\end{array}$ & $\begin{array}{l}33.70 \\
35.03 \\
34.36\end{array}$ & $\begin{array}{l}-4165 \\
-4442 \\
-4304\end{array}$ \\
\hline
\end{tabular}
${ }^{a}$ Stereo-designator and stereo-specific rate coefficient for molecules with 2 chiral centers. Also indicated is the geometric average over the
stereoisomers, as used in the kinetic model.

influence of the ring structure for H-migration across an epoxide ring. Similar to the findings of Novelli et al., we find that migration of an $\alpha$-epoxy $\mathrm{H}$-atom is not very favorable, despite the presence of an oxygen atom, and is only as fast as migration of an aliphatic $\mathrm{H}$-atom. All the calculated H-migrations are slow, $k(298 \mathrm{~K}) \leq 10^{-3} \mathrm{~s}^{-1}$, and do not contribute significantly in our experimental conditions.

\subsection{Isomerisation and decomposition of epoxidized nitrate-RO radicals}

The rate coefficients for decomposition and isomerisation of a set of $\beta$-epoxidized alkoxy radicals are listed in Table 7. Decomposition forming an $\alpha$-epoxy-alkyl radical is slow, due to high barriers owing to the increase in ring strain in these products. This is in agreement with our earlier work that found that a $\beta$-epoxy-moiety is less effective in lowering the barrier height for decomposition than alkyl or oxygenated substituents. ${ }^{49}$ Likewise, the barrier heights for the unfavorable elimination of a bare methyl radical product are comparatively high, making this reaction slow. Elimination of a - $\mathrm{CH}_{2} \mathrm{ONO}_{2}$ radical, where possible, is the most favorable decomposition; this radical readily decomposes further to $\mathrm{HCHO}+\mathrm{NO}_{2}$. The decomposition barriers for all these processes are reproduced within $1 \mathrm{kcal} \mathrm{mol}^{-1}$ by the SARs by Vereecken and Peeters ${ }^{38}$ and Novelli et al. ${ }^{38,49}$ The fastest reactions for the set of alkoxy radicals listed in Table 7 are syn-1,5-H-migrations across the epoxy moiety, either of a methyl $\mathrm{H}$-atom, or more favorably of a $-\mathrm{CH}_{2} \mathrm{ONO}_{2}$ hydrogen leading to $\mathrm{NO}_{2}$ elimination. As already anticipated by Novelli et al. ${ }^{49}$ the rate coefficients for H-migration across the epoxy moiety are within a factor of 2 of the rate of isomerisation in aliphatic alkoxy radicals (see SAR by Vereecken and Peeters ${ }^{57,60}$ ), where the $\alpha-\mathrm{ONO}_{2}$ substituent has a similar impact on the rate as an alkyl group.

\section{Chemical mechanism implementation}

The reactions and their theory-derived rate coefficients described in the earlier sections embedded in extended oxidation mechanisms for the relevant $\mathrm{RO}_{2}$ and $\mathrm{RO}$ radicals, are implemented in a zerodimensional box model, called $\mathrm{FZJ}-\mathrm{NO}_{3}$-isoprene henceforth, which can be used for modeling the trace gas concentration time series in the experiments.

As discussed higher, the rates of the re-equilibration reactions of the primary nitrate- $\mathrm{RO}_{2}$ radicals by $\mathrm{O}_{2}$-elimination/re-addiction are optimized to reproduce the theoretically derived $\mathrm{RO}_{2}$ equilibrium distribution in the absence of other loss processes. Since the system of variables is under-determined, we choose to approximate the oxygen addition rates to have the same rates as for the alkyl radicals in the $\mathrm{OH}+$ isoprene system. ${ }^{12-14}$ The ESI $\dagger$ lists $k(T)$ values for all isoprene-derived $\mathrm{RO}_{2}$ radicals, while the resulting rates at $298 \mathrm{~K}$ are illustrated in Fig. 2 for the main addition channel. Note that this approach only yields correct rate ratios between $\mathrm{O}_{2}$ addition and elimination, where the absolute magnitude of the values is inherited from the isoprene $+\mathrm{OH}+\mathrm{O}_{2}$ system. The site- and stereo-specificity of the initial $\mathrm{NO}_{3}$ addition is obtained from literature data (see above).

Unimolecular reaction rates for nitrate- $\mathrm{RO}_{2}$, nitrate- $\mathrm{RO}$, and epoxy-RO radicals from isoprene were taken from theoretical calculations in this work. Where necessary to derive extended oxidation schemes (see Fig. 4 and ESI $\dagger$ ), these were supplemented by application of the pertinent SARs. ${ }^{33,38,49,60}$ The $\mathrm{RO}_{2}$ bimolecular rate coefficients and product distributions were derived using the structure-activity relationship (SAR) by Jenkin et al. ${ }^{81}$ which does not explicitly incorporate the effect of the nitrate substituent. However, for the reaction rates for nitrate- $\mathrm{RO}_{2}+\mathrm{NO}_{3}$, we used the data by Dewald et al. ${ }^{46}$ In addition, an $\mathrm{OH}$-product channel is added to the reaction of $\beta-\mathrm{ONO}_{2}-\mathrm{RO}_{2}+\mathrm{HO}_{2}$, as introduced in earlier work. ${ }^{4,41-43,49,82}$

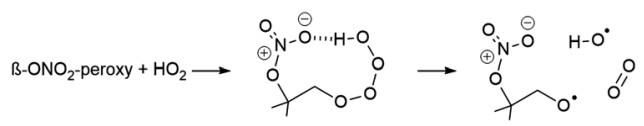

As discussed in Novelli et al. ${ }^{49}$ the mechanism for this reaction likely requires strong $\mathrm{H}$-bonding between the nitrate group and the $\mathrm{HO}_{x}$ moiety, or at least an inductive effect by a neighbouring nitrate group, which is possible for $\beta$-nitrate- $\mathrm{RO}_{2}+\mathrm{HO}_{2}$ but is unlikely to be effective for longer separations between the nitrate 
Table 7 Theoretical predictions for a series of epoxy-alkoxy and epoxy-nitrate-alkoxy radicals, at the CCSD(T)/aug-cc-pVTZ//M06-2X/aug-cc-pVTZ with MC-TST level of theory. Indicated are the ZPE-corrected barrier height $\left(E_{\mathrm{b}}\right.$, kcal mol $\left.{ }^{-1}\right)$, the $298 \mathrm{~K}$ rate coefficient $\left(\mathrm{k}(298 \mathrm{~K}), \mathrm{s}^{-1}\right)$, and the parameters for a Kooij expression $k(T)=A \times(T / K)^{n} \times \exp \left(-E_{\mathrm{a}} / T\right)\left(A\right.$ in $\mathrm{s}^{-1}, E_{\mathrm{a}}$ in $\left.\mathrm{K}\right)$

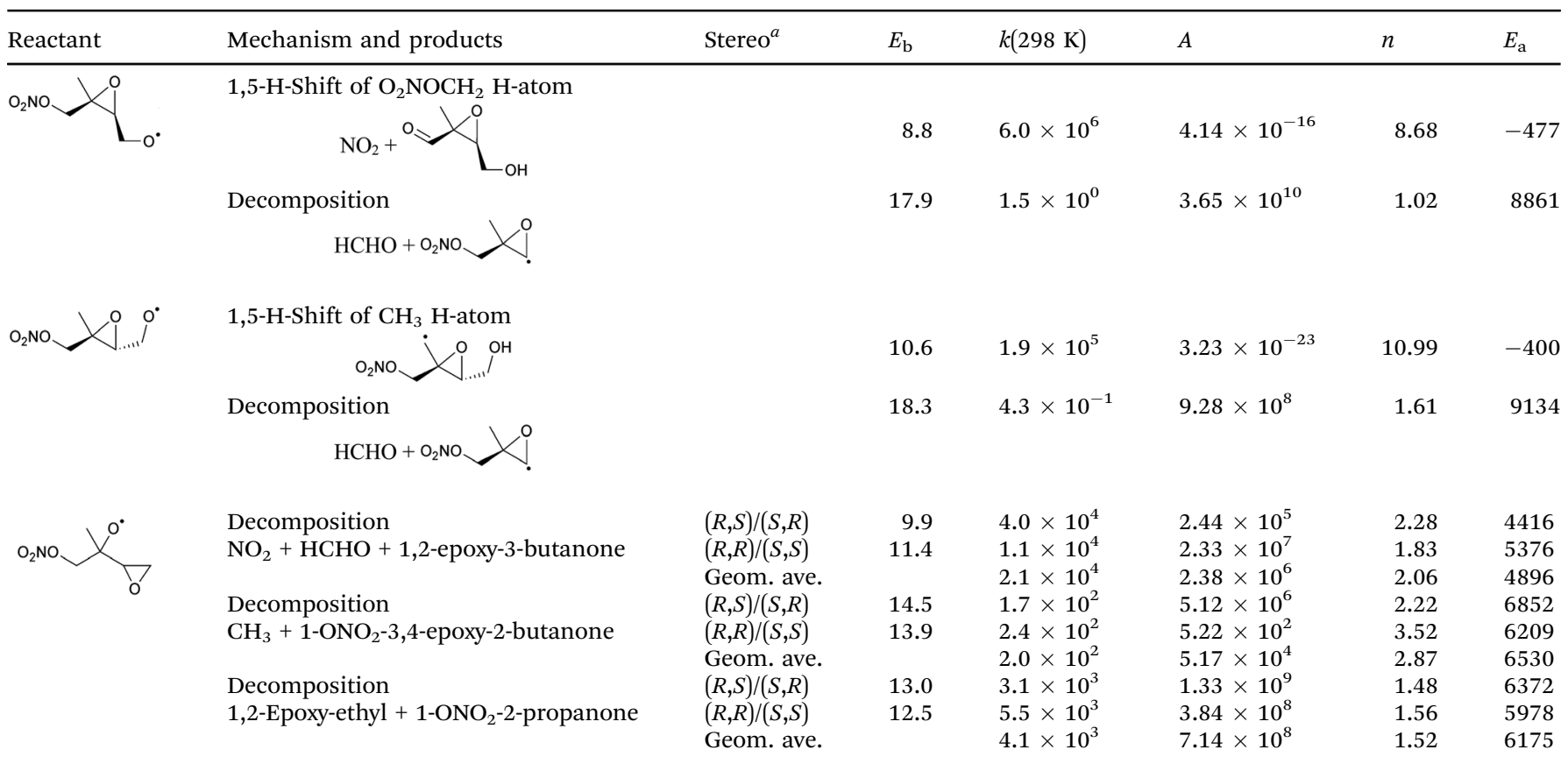

${ }^{a}$ Stereo-designator and stereo-specific rate coefficient for molecules with 2 chiral centers. Also indicated is the geometric average over the stereoisomers, as used in the kinetic model.

and peroxy groups. Contrary to the mechanism by Wennberg et $a .^{4}$ (called CalTech from here onward), we therefore do not include this channel for the $\gamma$ - and $\delta$-nitrate- $\mathrm{RO}_{2}$ radicals. At this time, we adopt a nitrate- $\mathrm{RO}+\mathrm{OH}$ yield of $\sim 50 \%$, compatible with the available literature, ${ }^{4,41-43,49}$ while retaining the total rate coefficient for an aliphatic $\mathrm{RO}_{2}+\mathrm{HO}_{2}$ reaction. This potentially underestimates the reaction rate somewhat, as similarly to the acylperoxy $+\mathrm{HO}_{2}$ reaction, the $\mathrm{RO}+\mathrm{OH}$ product channel (occurring on the singlet electronic surface) does not compete against the $\mathrm{ROOH}$ channel (proceeding on the triplet surface) but is rather an additional reaction pathway that enhances the total

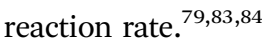

As we focus mainly on the formation and consumption of the initial $\mathrm{RO}_{2}$, the subsequent chemistry of the products following $\mathrm{RO}_{2}$ uni- or bimolecular reactions is included following the CalTech mechanism or, if none is provided there, we adopt the chemistry as described by the Master Chemical Mechanism v3.3.1 ${ }^{34-36}$ (available at http://mcm.leeds.ac.uk). The isoprene ozonolysis mechanism is updated based on the literature data and is described in detail in the ESI. $\dagger$ The chemistry following the $\mathrm{NO}_{3}$-addition on the central carbons of isoprene is not fully expanded in our current model. The yields for these channels are expected to be low, and we currently do not have product information that would allow determining these yields. These channels are rendered inoperable

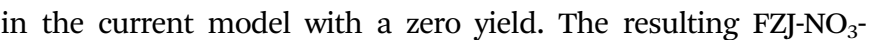
isoprene model is provided in the ESI. $\dagger$

For modeling the current set of experiments, the model also incorporates chamber-specific processes. A dilution coefficient was added for all trace gases in the model. This is necessary due to the replenishment flow required to keep the over-pressure in the chamber (see Experimental methodology). Isoprene, $\mathrm{O}_{3}$ and $\mathrm{NO}_{2}$ injections in the experiment were incorporated into the model as a short-period source reaction optimized to yield concentrations in agreement with their respective measurements, leaving these species concentrations otherwise unconstrained; Fig. S11 (ESI $\dagger$ ) shows a comparison of the measured against modelled isoprene concentrations. The concentration of $\mathrm{NO}_{3}$ was constrained to the measurement in order to reduce the impact of uncertainty in $\mathrm{NO}_{3}$ and/or $\mathrm{N}_{2} \mathrm{O}_{5}$ loss on the chamber wall, which can be significant ${ }^{46}$ and variable in time. Temperature, pressure and water content were also constrained to the measurements. As discussed in detail in the ESI, $\dagger$ there is an unresolved discrepancy between the modelled $\mathrm{HO}_{2}$ concentration in the simulations, and the $\mathrm{HO}_{2}$ measurement from the LIF system, with the latter higher by up to a factor of 10 . Two limiting cases are considered: (i) the discrepancy is assumed to be solely due to missing sources of $\mathrm{HO}_{2}$ radicals in the models, and therefore the modelled $\mathrm{HO}_{2}$ concentration is constrained to the measured $\mathrm{HO}_{2}$ radicals, and (ii) the discrepancy is assumed to be fully due to $\mathrm{RO}_{2}$ radicals interfering in the LIF $\mathrm{HO}_{2}$ measurement, ${ }^{67}$ and the $\mathrm{HO}_{2}$ and $\mathrm{RO}_{2}$ measurement are corrected for accordingly. These two limiting cases allows bracketing the impact of the uncertainty on the $\mathrm{HO}_{2}$ radical concentrations in the experiments described. It is important to underline that the chemical conditions within the experiments described in this study, specifically the lack of $\mathrm{NO}$, result in much larger $\mathrm{RO}_{2}$ radical concentrations as compared to the $\mathrm{HO}_{2}$ radicals (a factor of 10 more). Therefore, 
even a small interference (less than 10\%) from the $\mathrm{RO}_{2}$ radicals would drastically affect the measured $\mathrm{HO}_{2}$ radicals (Fig. S9, ESI $\dagger$ ).

The main differences between the MCM v3.3.1, CalTech, and FZJ-NO $\mathrm{N}_{3}$-isoprene models can be summarized as follows. The CalTech mechanism by Wennberg et al. ignores the stereospecificity of the $\delta$ - $\mathrm{NO}_{3}$-isoprene-OO isomers, lumping the $Z$ - and $E$-isomers into a single species despite their distinct chemistry both at the $\mathrm{RO}_{2}$ and the subsequent RO stage. After $\mathrm{NO}_{3}$ addition on isoprene, the CalTech model favors $\mathrm{O}_{2}$ addition on the $\delta$-position over the $\beta$-position, whereas the $\mathrm{FZJ}^{-\mathrm{NO}_{3}}$ isoprene model predicts a much higher contribution of the $\beta-\mathrm{ONO}_{2}-\mathrm{RO}_{2}$ radicals based on the theoretical Boltzmann distribution (Fig. 3). The CalTech mechanism also does not include the reversible epoxidation reactions for $\beta$-unsaturated nitrate-RO. Finally, the CalTech mechanism applies an $\mathrm{OH}$-forming channel in the nitrate- $\mathrm{RO}_{2}+\mathrm{HO}_{2}$ reaction irrespective of the distance between the $-\mathrm{ONO}_{2}$ and $-\mathrm{OO}^{\bullet}$ substituents, whereas $\mathrm{FZJ}^{-\mathrm{NO}_{3}}$ isoprene considers this path viable only for $\beta$-nitrate- $\mathrm{RO}_{2}$. The MCM v3.3.1 model incorporates only a single nitrate- $\mathrm{RO}_{2}$ isomer with limited subsequent chemistry. As such, it does not yet include nuances in chemistry such as the $\mathrm{RO}_{2}$ re-equilibration (which is implemented for isoprene $+\mathrm{OH}$ ), $\mathrm{RO}_{2}$ unimolecular reactions, epoxidation in nitrate-RO, or the $\mathrm{OH}$-channel in nitrate- $\mathrm{RO}_{2}+\mathrm{HO}_{2}$.

\section{Prediction of the ROxLIF detectable $\mathrm{RO}_{2}$ fraction}

The $\mathrm{RO}_{2}$ radicals are sampled from the SAPHIR chamber in the ROxLIF converter at a lower pressure $(25 \mathrm{hPa})$, and NO is added; due to the low pressure, bimolecular reactions other than with $\mathrm{NO}$ and $\mathrm{O}_{2}$ are negligible. During the residence time in the ROxLIF converter, $\sim 0.6 \mathrm{~s}$, the $\mathrm{RO}_{2}$ radicals react with $\mathrm{NO}$ forming RO radicals, which in turn are expected to convert to $\mathrm{HO}_{2}$, as described below. Finally, the ROxLIF system measures the $\mathrm{HO}_{2}$ concentration by sampling in a fluorescence cell, where $\mathrm{HO}_{2}$ gets converted to $\mathrm{OH}$ in reaction with $\mathrm{NO}$, and detected by LIF. The ROxLIF system thus measures the sum of $\mathrm{HO}_{2}$ formed from $\mathrm{RO}_{2}$ in the converter, and the $\mathrm{HO}_{2}$ radicals already present in the sampled SAPHIR chamber air; subtracting the SAPHIR $\mathrm{HO}_{2}$ and $\mathrm{OH}$ concentrations as measured directly by two additional and separate fluorescence cells ( $\mathrm{OH}$ and $\mathrm{HO}_{x}$ cells) then yields the $\mathrm{HO}_{2}$ signal attributable to conversion of $\mathrm{RO}_{2}$. Calibration of this signal relative to a known $\mathrm{CH}_{3} \mathrm{O}_{2}$ standard allows determination of absolute total $\mathrm{RO}_{2}$ concentrations, thus accounting for residence time, wall losses, and other characteristics of the converter.

The observation of $\mathrm{RO}_{2}$ radicals in the ROxLIF instrument thus hinges on the formation of $\mathrm{OH}$ or $\mathrm{HO}_{2}$ radicals from the alkoxy radicals derived from these $\mathrm{RO}_{2}$ radicals under the highNO conditions of the converter. Aliphatic and hydroxylated alkoxy radicals react with $\mathrm{O}_{2}$ (R5) and (R6), possibly after one or more decomposition steps, to form $\mathrm{HO}_{2}$ and are thus typically detectable. However, as already studied in detail by Novelli et al. ${ }^{49}$ nitrate-substituted $\mathrm{RO}_{2}$ radicals can undergo chain termination by decomposition of the nitrate group (R7), forming $\mathrm{NO}_{2}$, and are thus undetectable in the ROxLIF measurement.

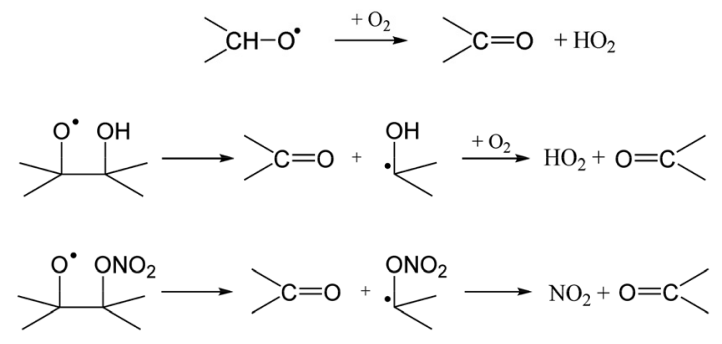

Also, if the alkoxy radical isomerises, e.g. by H-migration or epoxidation, followed by $\mathrm{O}_{2}$ addition, the resulting new $\mathrm{RO}_{2}$ radical must again react with $\mathrm{NO}$ to allow $\mathrm{HO}_{2}$ formation. Thus, dependent on the residence time and NO concentration in the converter, some $\mathrm{RO}_{2}$ may not yield $\mathrm{HO}_{2}$. Such additional steps can thus lead to reduced conversion of the parent $\mathrm{RO}_{2}$ to $\mathrm{HO}_{2}$.

To aid the interpretation of the $\mathrm{RO}_{2}$ measurements in the $\mathrm{NO}_{3}$-initiated oxidation experiments on isoprene, we modelled the fate of the $\mathrm{RO}_{2}$ radicals under the reaction conditions in the converter $(25 \mathrm{hPa}, 0.55 \mathrm{ppmv}$ of $\mathrm{NO}, 0.17 \% \mathrm{CO}$, residence time

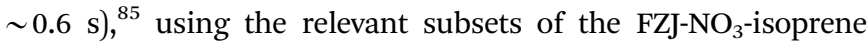
model for the target $\mathrm{RO}_{2}$ radicals. From these model calculations, we find that the isoprene-derived nitrate- $\mathrm{RO}_{2}$ radicals, and the $\mathrm{RO}_{2}$ radicals formed in their subsequent reactions in the SAPHIR chamber, are not converted fully to $\mathrm{OH}$ or $\mathrm{HO}_{2}$ radicals but rather generate $\mathrm{NO}_{2}$ under the conditions in the converter, and will thus remain partially invisible in the LIF measurement of $\mathrm{RO}_{2}$. For example, at $298 \mathrm{~K}$ the main nitrate- $\mathrm{RO}_{2}$ species $1-\mathrm{NO}_{3}$-isoprene-2$\mathrm{OO}^{\bullet}$ and $1-\mathrm{NO}_{3}$-isoprene-4-OO ${ }^{\bullet}$ are estimated to produce only $25 \%$ and $11-15 \% \mathrm{HO}_{x}$, respectively, in the fluorescence cell relative to the calibrating $\mathrm{CH}_{3} \mathrm{O}_{2}$ radical, with the remainder forming undetectable $\mathrm{NO}_{2}$ or remaining as one of the intermediate $\mathrm{RO}_{2}$. For the nitrate- $\mathrm{RO}_{2}$ formed in the minor addition channel, 4- $\mathrm{NO}_{3}$-isoprene-3-OO ${ }^{\bullet}$ and $4-\mathrm{NO}_{3}$-isoprene-1-OO${ }^{\bullet}$, less than $3 \%$ are predicted to be detectable. The temperaturedependent detectability for all relevant nitrate- $\mathrm{RO}_{2}$ and nitrateepoxy- $\mathrm{RO}_{2}$ is listed in Table $\mathrm{S} 2$ in the ESI. $\dagger$ The ROxLIF instrument in use at the SAPHIR chamber is thus not expected to return the sum of all $\mathrm{RO}_{2}$ concentrations (called "total $\mathrm{RO}_{2}$ " hereafter) as predicted in the model, but measurements instead correspond to the summation of all $\mathrm{RO}_{2}$ concentrations weighted by their speciated $\mathrm{HO}_{x}$ yields to obtain the so-called "detectable $\mathrm{RO}_{2}$ " sum. For non-nitrated $\mathrm{RO}_{2}$, we adopt unity $\mathrm{HO}_{2}$ formation efficiency relative to the calibrating $\mathrm{CH}_{3} \mathrm{O}_{2}$ radical. ${ }^{85}$ As the relative nitrate$\mathrm{RO}_{2}$ radical detectability depends on the conditions in the converter and fluorescence cell, e.g. NO concentration, pressure, etc., the detectability can't be generalized to other ROxLIF instruments, and each system needs to be experimentally characterized. The a priori predictions of the detectability in the current work do not benefit from any such experimental calibration, and are thus affected by the combined uncertainties on temperature, pressure, converter and fluorescence cell residence time, wall losses, rate coefficients, chemical activation, and possible unknown reactions in a complex reaction mechanism. Several of these aspects are discussed in more detail in the ESI. $\dagger$ Overall, we 
estimate an uncertainty of about a factor of 2 to 3 on the estimated relative conversion efficiency governing the detectability of $\mathrm{RO}_{2}$, mostly due to the uncertainties on the various rate coefficients in the kinetic model used to derive these conversion efficiencies. It must be stressed that the reduced $\mathrm{O}_{2}$ concentrations in the converter affects the chemistry rather significantly. Under atmospheric conditions, formation of epoxy- $\mathrm{RO}_{2}$ is expected to be more prevalent, whereas in the converter, direct alkoxy decomposition and isomerisation reactions are more competitive.

\section{Comparison to experimental observations}

\subsection{Peroxy radical concentration}

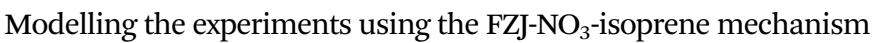
indicates that oxidation of isoprene by $\mathrm{NO}_{3}$ was the dominant degradation pathway, with $10-15 \%$ of isoprene oxidized each by ozone and hydroxyl radicals. Isoprene ozonolysis forms mainly stable products and has only a small contribution to the $\mathrm{RO}_{2}$ pool; these ozone- $\mathrm{RO}_{2}$ are not discussed further in this work. $\mathrm{RO}_{2}$ radicals from the oxidation of isoprene by $\mathrm{OH}$ radicals contribute about $20 \%$ to the total $\mathrm{RO}_{2}$ according to our model, and all these $\mathrm{RO}_{2}$ are detectable in the ROxLIF instrument. ${ }^{38,49,60}$ The bulk of the $\mathrm{RO}_{2}$ radicals in the reaction mixture of the experiments, however, is nitrate- $\mathrm{RO}_{2}$ radicals which, as discussed above, are only partially detectable (see Fig. S14 in the ESI $\dagger$ ). As shown in Fig. 5 and additional figures in the ESI, $\dagger$ we predict for all three experiment days large discrepancies between the total $\mathrm{RO}_{2}$ and the $\mathrm{RO}_{2}$ detected by the ROxLIF instrument. The modelled detectable $\mathrm{RO}_{2}$, however, differs from the measured $\mathrm{RO}_{2}$ concentration only by about a factor of 2, if the $\mathrm{FZJ}-\mathrm{NO}_{3}$-isoprene chemical mechanism is applied. The fate of the nitrate- $\mathrm{RO}_{2}$ is strongly affected by the $\mathrm{O}_{2}$-driven $\mathrm{RO}_{2}$ re-equilibration as implemented in the $\mathrm{FZJ}^{-\mathrm{NO}_{3}}$ isoprene model. This re-equilibration is rapid compared to the rate of $\mathrm{RO}_{2}$ loss processes, such that the instantaneous $\mathrm{RO}_{2}$ population is always close to the equilibrium fractions, with 1- $\mathrm{NO}_{3}$-isoprene-2peroxy radicals being the dominant $\mathrm{RO}_{2}$ species (Fig. 3), with 70 to $75 \%$ contribution in the $1-\mathrm{NO}_{3}$-isoprene peroxy radical pool, depending on the temperature. This tertiary peroxy radical acts as a reservoir species, owing to its comparatively slow bimolecular loss processes $\left(k \sim 1.6 \times 10^{-2} \mathrm{~s}^{-1}\right.$ for $\mathrm{HO}_{2} / \mathrm{RO}_{2} / \mathrm{NO}_{3}$ combined, see below), ${ }^{81}$ and combined with the slow unimolecular reactions $\left(k \sim 1.8 \times 10^{-3} \mathrm{~s}^{-1}\right.$, Table 3$)$ this leads to lifetimes of about $2 \mathrm{~min}$ for $1-\mathrm{NO}_{3}-\mathrm{RO}_{2}$ radicals. In contrast, bimolecular and unimolecular reactions of 4-nitrooxy $\mathrm{RO}_{2}$ radicals have overall higher (pseudofirst order) rate coefficients (respectively $2.1 \times 10^{-2}$ and $1.1 \times$ $10^{2} \mathrm{~s}^{-1}$, Table 3), have lifetimes of around $1 \mathrm{~min}$, and contribute significantly less to the $\mathrm{RO}_{2}$ concentration. Table 8 list the contributions of the respective loss processes for each nitrate$\mathrm{RO}_{2}$. Overall, the majority of the nitrate- $\mathrm{RO}_{2}$ are lost by reaction with $\mathrm{HO}_{2}$ and $\mathrm{NO}_{3} \cdot \mathrm{RO}_{2}+\mathrm{RO}_{2}$ reactions are never dominant, even for the experiment with the highest modelled peak $\mathrm{RO}_{2}$ concentrations in excess of $8 \times 10^{9}$ molecule $\mathrm{cm}^{-3}$. Some nitrate- $\mathrm{RO}_{2}$ have a fast unimolecular loss channel, which can
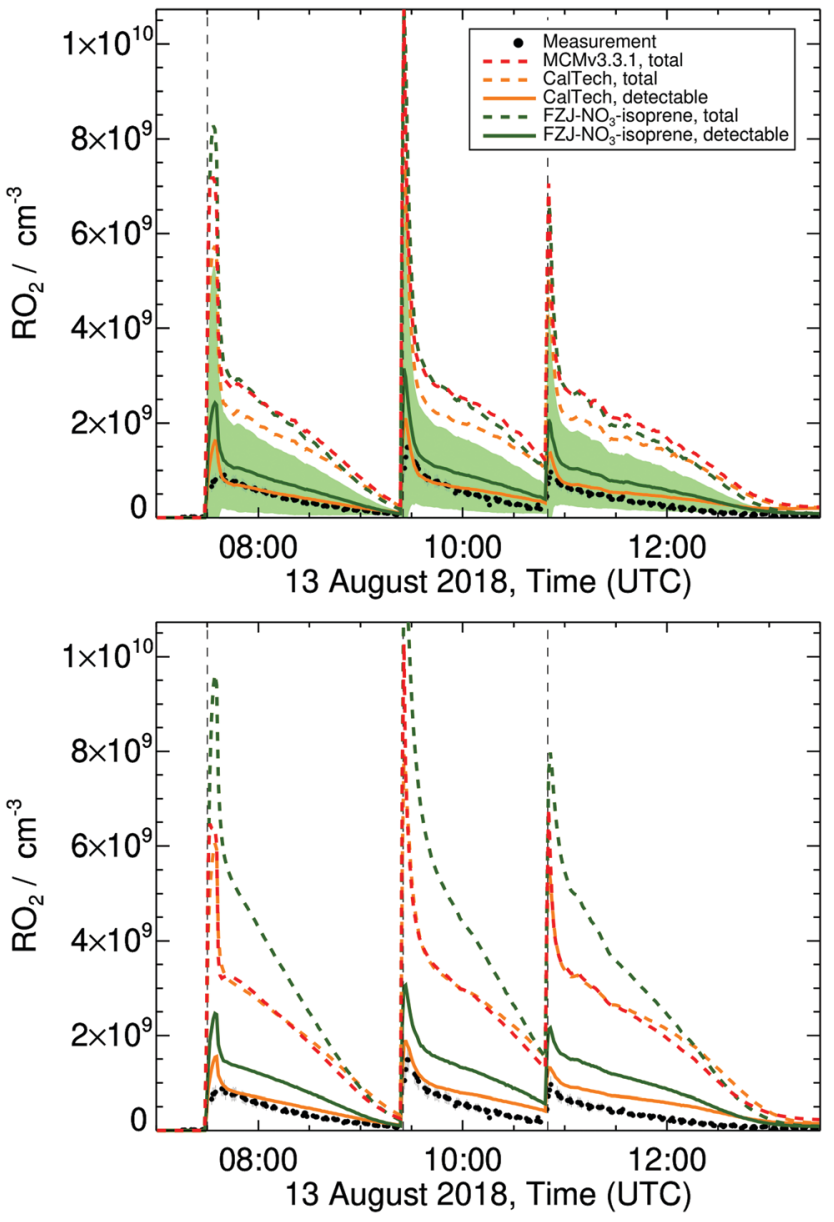

Fig. 5 Measured and modelled $\mathrm{RO}_{2}$ concentration time profiles for the experiment on 13 Aug 2018, as described in Dewald et al., ${ }^{46}$ with reaction conditions shown in $\mathrm{ESI} \uparrow$ Section $\mathrm{K}$. Dashed lines represent the total $\mathrm{RO}_{2}$ predicted by the models; upper panel: model results with $\mathrm{HO}_{2}$ constrained to measurements, bottom panel: unconstrained $\mathrm{HO}_{2}$. For the more detailed CalTech and $\mathrm{FZJ}-\mathrm{NO}_{3}$-isoprene models, additional traces (solid lines) show the estimated detectable $\mathrm{RO}_{2}$, which can be compared to the measurements. The shaded area shows a factor of 2 uncertainty on the estimated conversion efficiency factors of the detectable $\mathrm{RO}_{2}$ predicted by the $\mathrm{FZJ}-\mathrm{NO}_{3}$-isoprene model.

become the dominant loss path for these specific isomers but has only a small overall contribution.

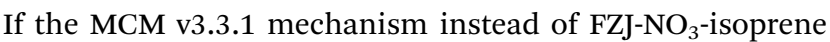
is used in the model, the nitrate- $\mathrm{RO}_{2}$ population is represented by a single $\mathrm{RO}_{2}$ isomer $\left(E-1-\mathrm{NO}_{3}\right.$-isoprene-4-OO$\left.{ }^{\bullet}\right)$ and at room temperature only $15 \%$ of this $\mathrm{RO}_{2}$ isomer would be detectable in the ROxLIF. However, due to the reduction in the MCM to only one $\mathrm{RO}_{2}$ isomer, measured and modelled $\mathrm{RO}_{2}$ concentrations can hardly be compared.

If the CalTech mechanism is applied, the predicted detectable $\mathrm{RO}_{2}$ also reproduces the experimental measurements well (Fig. 5), indicating that the more refined description of the

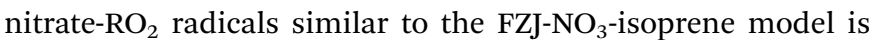
beneficial. The lower ratio of $1-\mathrm{NO}_{3}$-isoprene-2-OO ${ }^{\bullet}$ to $1-\mathrm{NO}_{3}$ isoprene-4-OO ${ }^{\bullet}$ radicals in the CalTech mechanism compared to the $\mathrm{FZJ}-\mathrm{NO}_{3}$-isoprene mechanism leads to a shorter chemical 
Table 8 Modelled fates of the nitrate- $\mathrm{RO}_{2}$, averaged across the three experiment days. $\mathrm{HO}_{2}$ concentrations were in the range of $0.1-8 \times 10^{8}$ molecule $\mathrm{cm}^{-3}, \mathrm{NO}_{3}$ concentrations were in the range of $1-50 \times 10^{8}$ molecule $\mathrm{cm}^{-3}$, and sustained $\mathrm{RO}_{2}$ concentrations were at $1-3 \times 10^{9} \mathrm{molecule} \mathrm{cm}^{-3}$. The range or value before the slash shows the fates when constraining $\mathrm{HO}_{2}$ concentrations to the measurement, and uses an $\mathrm{HO}_{2}$ concentration of

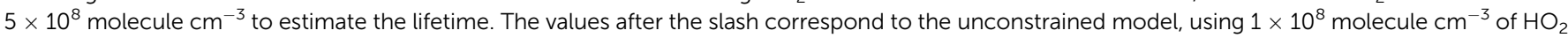
for the lifetime estimate

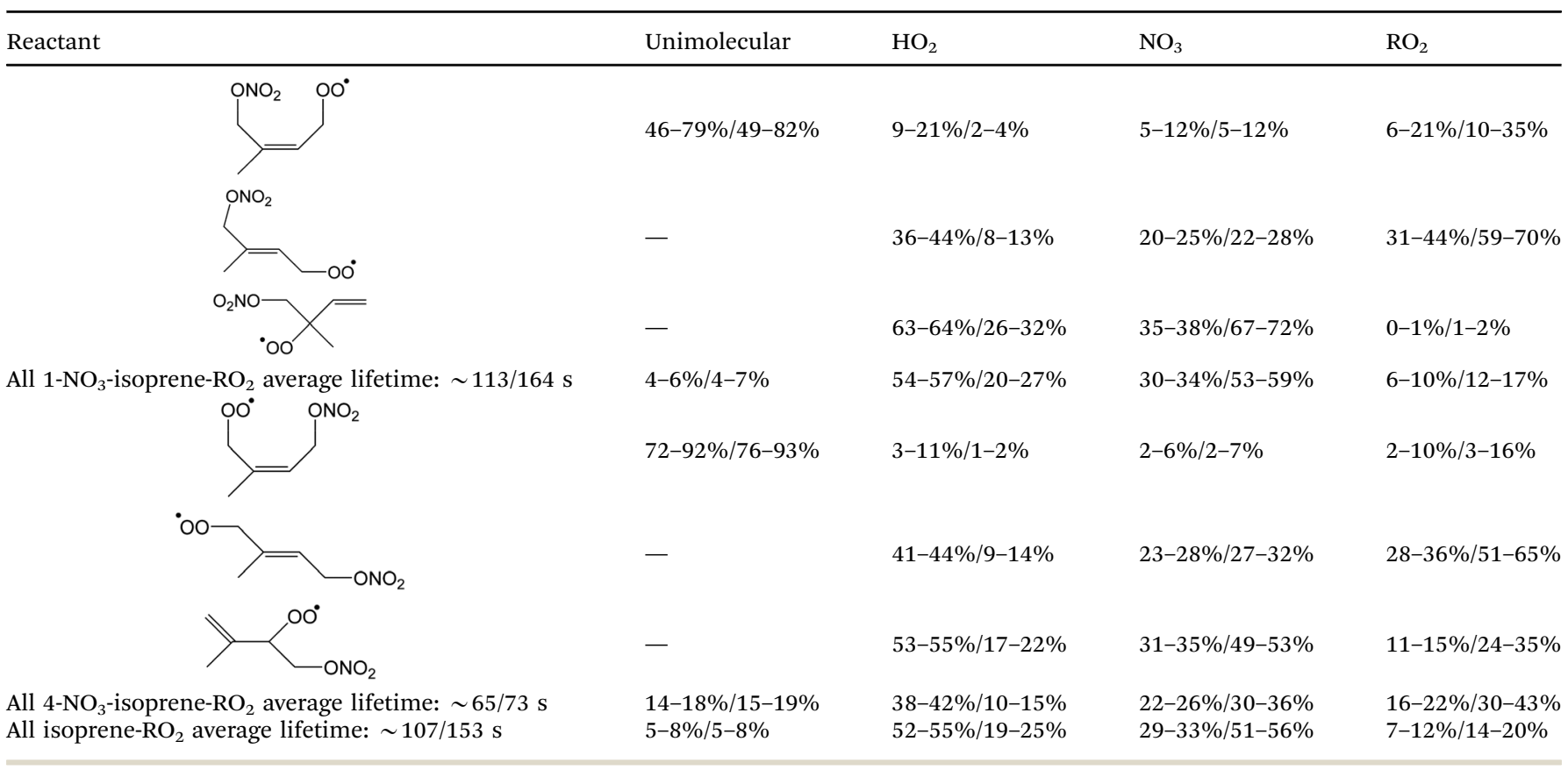

lifetime of the nitrate- $\mathrm{RO}_{2}$ and hence lower $\mathrm{RO}_{2}$ concentrations. Given the uncertainty of the estimated detectability, however, we cannot confirm that these lower predicted detectable $\mathrm{RO}_{2}$ concentrations are in better agreement with the experiment. The $\mathrm{RO}_{2}$ concentrations predicted with the CalTech mecha-

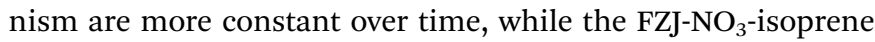
mechanism follows a more gradual decrease in $\mathrm{RO}_{2}$ concentration (Fig. 5). This suggests that the modeling of the $\mathrm{RO}_{2}$ population may be further improved by explicitly incorporating the distinct stereo-specific chemistry of $Z$ - and $E$-nitrate- $\mathrm{RO}_{2}$ radicals, and basing the nitrate- $\mathrm{RO}_{2}$ populations on the theory-

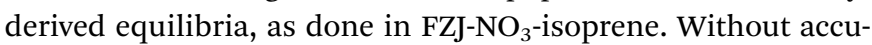
rate calibration of the detectability of the nitrate- $\mathrm{RO}_{2}$, it is hard to further characterize the relative performance of the CalTech and FZJ-NO $\mathrm{N}_{3}$-isoprene mechanisms on the $\mathrm{RO}_{2}$ concentration. This is especially true for later times in the experiment where secondary chemistry becomes increasingly important, and the uncertainty in the modelled value increases as the chemical mechanism for these species has not yet been updated to the latest chemical insights.

\subsection{Methyl vinyl ketone and methacrolein yields}

Prominent stable products from isoprene oxidation are methyl vinyl ketone (MVK) and methacrolein (MACR), produced from and destroyed by various reaction channels such as ozonolyis, $\mathrm{NO}_{3}$ and $\mathrm{OH}$ reactions. ${ }^{4}$ Therefore, differences between measured and modelled MVK and MACR concentrations can be caused by incorrect production or loss from either one of the pathways. For the conditions of the experiments in this work,
$80 \%$ of isoprene is lost in the reaction with $\mathrm{NO}_{3}$. In the $\mathrm{FZJ}^{-\mathrm{NO}_{3}-}$ isoprene model, however, less than $1 \%$ of the modelled MVK and MACR concentrations originate from the $\mathrm{NO}_{3}+$ isoprene oxidation. The remaining part is formed through the isoprene + $\mathrm{OH}$ chemistry (80\%) and through ozonolysis (19\%) although these two channels represent only $\sim 10-15 \%$ each of the isoprene loss. The $\mathrm{FZJ}-\mathrm{NO}_{3}$-isoprene mechanism reproduces the measured MVK + MACR concentrations within 25\% (Fig. 6 and additional figures in the ESI $\dagger$ ). This difference is close to the uncertainty of the MVK and MACR yields in the mechanism and the measurement uncertainty $( \pm 14 \%)$. The latter is partially due to the difference in sensitivities for MVK and MACR in the VOCUS PTR-MS, such that the comparison depends on the knowledge of the MACR to MVK ratio.

Applying the MCM v3.3.1 mechanism, MVK + MACR concentrations are reproduced within $15 \%$, even though no formation of these compounds from $\mathrm{NO}_{3}$ chemistry is included. This is compensated by a higher MVK yield from isoprene ozonolysis, compared to the $\mathrm{FZJ}_{-} \mathrm{NO}_{3}$-isoprene scheme (see ESI $\dagger$ ). In contrast

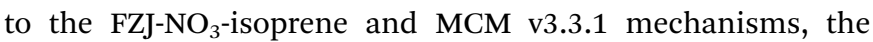
CalTech mechanism overestimates MVK + MACR concentrations by between 250 to $400 \%$, mainly due to the complete conversion of $1-\mathrm{NO}_{3}$-isoprene-2- ${ }^{\bullet}$ radicals, formed in the 1- $\mathrm{NO}_{3}$-isoprene-2-

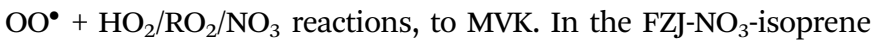
model these nitrate-RO radicals are also formed, but their decomposition to MVK is overwhelmed by the epoxidation reactions described above. Without the competing epoxidation channel, the $\mathrm{MVK}+\mathrm{MACR}$ concentration predicted by FZJ-NO ${ }_{3}$-isoprene would even exceed that predicted by CalTech model, owing to the larger 

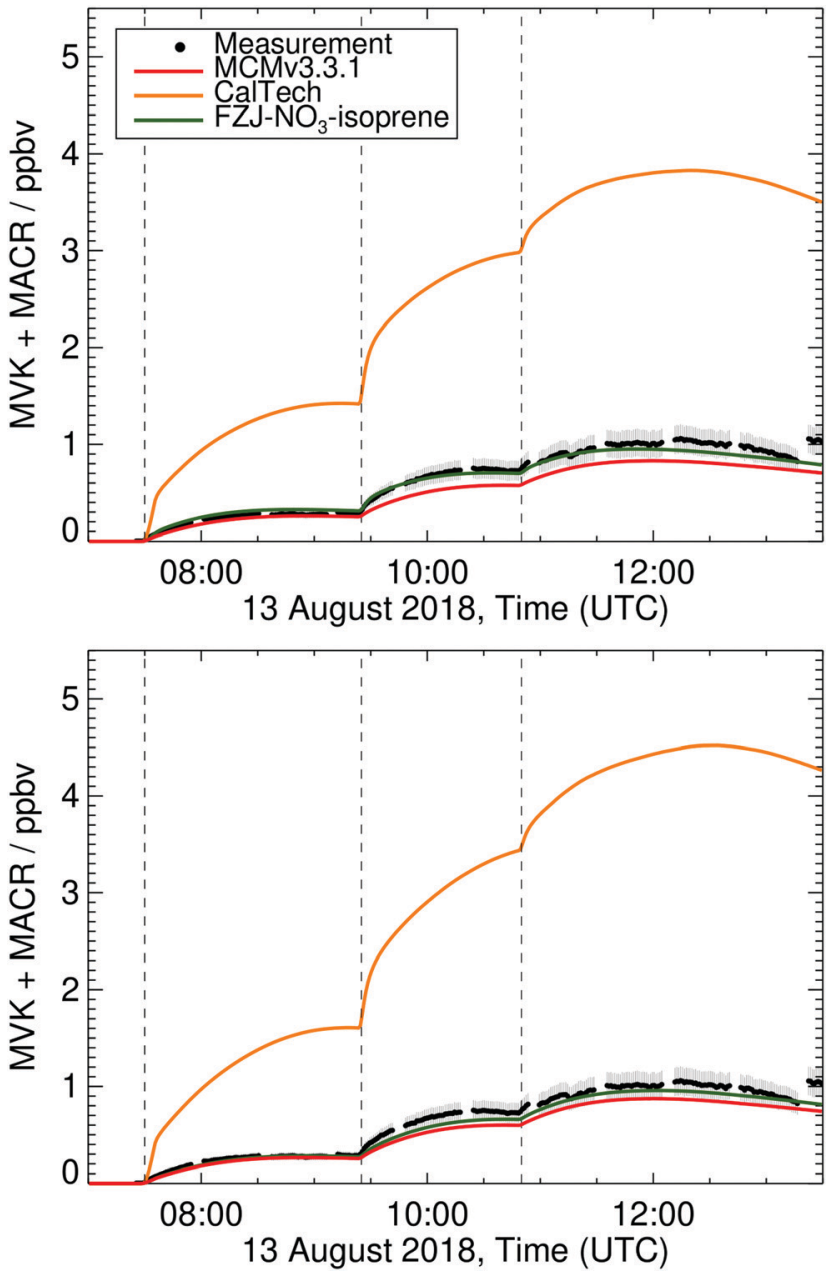

Fig. 6 Measured and modelled methyl vinyl ketone + methacrolein (MVK + MACR) concentration time profiles for the experiment on 13 Aug 2018 as described in Dewald et al., ${ }^{46}$ with reaction conditions shown in ESI $\dagger$ Section K. Upper panel: Model results with $\mathrm{HO}_{2}$ constrained to measurements; bottom panel: unconstrained $\mathrm{HO}_{2}$. The measurement assumes equal amounts of MVK and MACR are present to account for the differing sensitivities. For the conditions present in these experiments, this assumption is validated by the modelling.

fraction of $1-\mathrm{NO}_{3}$-isoprene-2-OO radicals in the nitrate- $\mathrm{RO}_{2}$ population. A prominent source of $1-\mathrm{NO}_{3}$-isoprene-2-O ${ }^{\bullet}$ radicals is the reaction of nitrate- $\mathrm{RO}_{2}+\mathrm{HO}_{2}$ forming nitrate- $\mathrm{RO}+\mathrm{OH}$ (reaction (R4)). The need for $\mathrm{OH}$ formation in this channel as put to evidence by other experimental studies, ${ }^{41-43}$ combined with the low measured MVK + MACR concentrations in our experiments indirectly validates the proposed epoxidation with $\mathrm{O}_{2}$ addition chemistry in the $\mathrm{FZJ}-\mathrm{NO}_{3}$-isoprene model. Due to the competing, faster bimolecular reactions and its lower yield, the decomposition of the $4-\mathrm{NO}_{3}$-isoprene-3-OO ${ }^{\bullet}$ to MACR only plays a minor role.

\section{Conclusions}

The $\mathrm{NO}_{3}$-initiated chemistry of isoprene appears to be as complex as the $\mathrm{OH}$-initiated oxidation of isoprene. The available theoretical and experimental data indicates that, similar to the
LIM-mechanism for OH-initiated oxidation, ${ }^{12,13}$ the initial steps of the isoprene $+\mathrm{NO}_{3}$ mechanism must take the siteand stereo-specificity of the $\mathrm{NO}_{3}$ and $\mathrm{O}_{2}$ addition into account, as well as the re-equilibration of the $\mathrm{RO}_{2}$ isomers by $\mathrm{O}_{2}$ elimination/re-addition. The nitrate- $\mathrm{RO}_{2}$ radicals show several reaction channels that may be competitive in pristine environments. For the main $\mathrm{NO}_{3}$-addition channels on the outer carbons of isoprene, the dominant unimolecular reactions of the $\mathrm{RO}_{2}$ formed, with $k(298 \mathrm{~K})$ up to $5 \times 10^{-2} \mathrm{~s}^{-1}$, are the migration of the $\mathrm{CH}_{2} \mathrm{ONO}_{2} \mathrm{H}$-atoms, forming HPALD $+\mathrm{NO}_{2}$, thus linking the mechanism to the $\mathrm{OH}$-initiated oxidation of isoprene where HPALD is thought to be a key intermediate in $\mathrm{OH}$ regeneration. ${ }^{14,19,86}$ The rate predictions for $\mathrm{RO}_{2} \mathrm{H}$-migration are found to be in good agreement with a recent SAR by Vereecken and Nozière ${ }^{33}$ for $\mathrm{H}$-migration in $\mathrm{RO}_{2}$ radicals. The rate coefficients for $\mathrm{H}$-migration in nitrate- $\mathrm{RO}_{2}$ are generally slower than in hydroxylated $\mathrm{RO}_{2}$, such that the impact of unimolecular $\mathrm{RO}_{2}$ chemistry in the atmosphere will be significantly less for isoprene $+\mathrm{NO}_{3}$ than for isoprene $+\mathrm{OH}$; at this time we have no experimental evidence for significant HPALD formation in the $\mathrm{NO}_{3}$-initiated oxidation. Only for the $\mathrm{RO}_{2}$ formed in the minor addition channels, i.e. with $\mathrm{NO}_{3}$ adding on the central carbons, are fast ring closure reactions with $k(298 \mathrm{~K})$ exceeding $1 \mathrm{~s}^{-1}$ possible that might prove competitive against bimolecular reactions, and might lead to highly oxygenated molecules, albeit in small yields. We observed no products we could assign uniquely to these channels.

The chemistry of the nitrated alkoxy radicals shows several fast decomposition and isomerisation reactions leading to the fragmentation of the nitrate group, forming a carbonyl compound and $\mathrm{NO}_{2}$. Decomposition and isomerisation reactions of nitrate$\mathrm{RO}$ radicals are typically slower than in the analogous $\mathrm{OH}^{-}$ substituted alkoxy radicals, ${ }^{38,49,60}$ allowing epoxidation reactions in unsaturated nitrate-RO to become competitive. The role of these epoxidized compounds is not fully elucidated yet, but has important impact on the predicted product formation. For example, the theoretical predictions indicate a very small yield of methyl-vinyl-ketone (MVK) from 1- $\mathrm{NO}_{3}$-isoprene-2-O radicals, contrary to expectations by Wennberg et al. ${ }^{4}$ The predicted MVK + MACR yields are in good agreement with the experimental observations, provided epoxidation is taken into account. The formation of epoxides could indicate a higher propensity for aerosol formation at nighttime due to reactive uptake on particles. Still, a strong contribution of epoxidation also does not necessarily imply a high yield of epoxidized products, as the epoxide may undergo ring opening in subsequent reaction steps. For example, the dominant epoxidation channel in the important $1-\mathrm{NO}_{3}$ isoprene-2- $0^{\bullet}$ radical still leads mainly to non-epoxidized nitrated MACR, due to ring reopening after a hydrogen shift (Fig. 4).

As predicted in a recent study by Novelli et al., ${ }^{49}$ the observation of nitrated $\mathrm{RO}_{2}$ radicals formed from isoprene using a LIF instrument by their conversion to alkoxy radicals and ultimately $\mathrm{HO}_{2}$ with an excess $\mathrm{NO}$ is not straightforward, owing to the potential $\mathrm{NO}_{2}$ elimination. When considering this chemistry in the comparison between model and experiment, we find that less than a third of the nitrate- $\mathrm{RO}_{2}$ are detectable, and 
agreement within a factor $\sim 2$ is obtained, subject to considerable uncertainties on the exact relative conversion efficiency.

Though the current work has characterized a large number of reactions important in the initial stages of the $\mathrm{NO}_{3}$-initiated oxidation of isoprene, further work is needed to elucidate the later stages of the chemistry. The theoretically characterized pathways may also be of importance in the $\mathrm{NO}_{3}$-driven atmospheric chemistry of other unsaturated organic compounds. Finally, though the results in this work are only weakly dependent on the $\mathrm{HO}_{2}$ concentration, further investigation of the cause of the difference between modelled and measured $\mathrm{HO}_{2}$ would be useful.

\section{Author contributions}

All authors contributed to the conceptualization, execution and discussion of the campaign on $\mathrm{NO}_{3}$-initiated isoprene oxidation. LV performed the quantum chemical and theoretical kinetic calculations, and derived the oxidation schemes. PC, LV and AN implemented the mechanisms and performed the modeling studies. HF and SSB planned the experiments and organized them. RT and DR provided isoprene and MVK + MACR data. FB, JC, SSB, WM, JS, and $\mathrm{LZ}$ provided $\mathrm{NO}_{3}$ data. AN and CC provided the $\mathrm{RO}_{2}$ and $\mathrm{HO}_{2}$ data. $\mathrm{LV}, \mathrm{AN}, \mathrm{PC}$, and $\mathrm{HF}$ wrote the paper.

\section{Conflicts of interest}

There are no conflicts to declare.

\section{Acknowledgements}

This research has received support by Horizon 2020 Projects EUROCHAMP-2020 (grant no. 730997) and SARLEP (grant no. 681529).

\section{References}

1 A. B. Guenther, X. Jiang, C. L. Heald, T. Sakulyanontvittaya, T. Duhl, L. K. Emmons and X. Wang, The model of emissions of gases and aerosols from nature version 2.1 (MEGAN2.1): An extended and updated framework for modeling biogenic emissions, Geosci. Model Dev., 2012, 5, 1471-1492.

2 R. P. Wayne, I. Barnes, P. Biggs, J. P. Burrows, C. E. CanosaMas, J. Hjorth, G. Le Bras, G. K. Moortgat, D. Perner, G. Poulet, G. Restelli and H. Sidebottom, The nitrate radical: Physics, chemistry, and the atmosphere, Atmos. Environ., 1991, 25, 1-203.

3 R. Atkinson, Gas-phase tropospheric chemistry of organic compounds: A review, Atmos. Environ., 2007, 41(Supplement), 200-240.

4 P. O. Wennberg, K. H. Bates, J. D. Crounse, L. G. Dodson, R. C. McVay, L. A. Mertens, T. B. Nguyen, E. Praske, R. H. Schwantes, M. D. Smarte, J. M. St Clair, A. P. Teng, $\mathrm{X}$. Zhang and J. H. Seinfeld, Gas-phase reactions of isoprene and its major oxidation products, Chem. Rev., 2018, 118, 3337-3390.

5 A. Geyer, B. Alicke, S. Konrad, T. Schmitz, J. Stutz and U. Platt, Chemistry and oxidation capacity of the nitrate radical in the continental boundary layer near Berlin, J. Geophys. Res.: Atmos., 2001, 106, 8013-8025.

6 B. J. Finlayson-Pitts and J. N. Pitts, Chemistry of the Upper and Lower Atmosphere: Theory, Experiments, and Applications, Academic Press, San Diego, 1999.

7 J. Liebmann, E. Karu, N. Sobanski, J. Schuladen, M. Ehn, S. Schallhart, L. Quelever, H. Hellen, H. Hakola, T. Hoffmann, J. Williams, H. Fischer, J. Lelieveld and J. N. Crowley, Direct measurement of $\mathrm{NO}_{3}$ radical reactivity in a boreal forest, Atmos. Chem. Phys., 2018, 18, 3799-3815.

8 C. Warneke, J. A. de Gouw, P. D. Goldan, W. C. Kuster, E. J. Williams, B. M. Lerner, R. Jakoubek, S. S. Brown, H. Stark, M. Aldener, A. R. Ravishankara, J. M. Roberts, M. Marchewka, S. Bertman, D. T. Sueper, S. A. McKeen, J. F. Meagher and F. C. Fehsenfeld, Comparison of daytime and nighttime oxidation of biogenic and anthropogenic VOCs along the New England coast in summer during New England Air Quality Study 2002, J. Geophys. Res.: Atmos., 2004, 109, D10309.

9 S. S. Brown, W. P. Dube, J. Peischl, T. B. Ryerson, E. Atlas, C. Warneke, J. A. de Gouw, S. te, L. Hekkert, C. A. Brock, F. Flocke, M. Trainer, D. D. Parrish, F. C. Feshenfeld and A. R. Ravishankara, Budgets for nocturnal VOC oxidation by nitrate radicals aloft during the 2006 Texas Air Quality Study, J. Geophys. Res.: Atmos., 2011, 116, D24305.

10 J. M. Liebmann, J. B. A. Muller, D. Kubistin, A. Claude, R. Holla, C. Plass-Duelmer, J. Lelieveld and J. N. Crowley, Direct measurements of $\mathrm{NO}_{3}$ reactivity in and above the boundary layer of a mountaintop site: Identification of reactive trace gases and comparison with $\mathrm{OH}$ reactivity, Atmos. Chem. Phys., 2018, 18, 12045-12059.

11 J. Liebmann, N. Sobanski, J. Schuladen, E. Karu, H. Hellén, H. Hakola, Q. Zha, M. Ehn, M. Riva, L. Heikkinen, J. Williams, H. Fischer, J. Lelieveld and J. N. Crowley, Alkyl nitrates in the boreal forest: formation via the $\mathrm{NO}_{3^{-}}, \mathrm{OH}-$ and $\mathrm{O}_{3}$-induced oxidation of biogenic volatile organic compounds and ambient lifetimes, Atmos. Chem. Phys., 2019, 19, 10391-10403.

12 J. Peeters, T. L. Nguyen and L. Vereecken, HOx radical regeneration in the oxidation of isoprene, Phys. Chem. Chem. Phys., 2009, 11, 5935-5939.

13 J. Peeters, J.-F. J. Müller, T. Stavrakou and V. S. Nguyen, Hydroxyl radical recycling in isoprene oxidation driven by hydrogen bonding and hydrogen tunneling: The upgraded LIM1 mechanism, J. Phys. Chem. A, 2014, 118, 8625-8643.

14 A. Novelli, L. Vereecken, B. Bohn, H.-P. Dorn, G. I. Gkatzelis, A. Hofzumahaus, F. Holland, D. Reimer, F. Rohrer, S. Rosanka, D. Taraborrelli, R. Tillmann, R. Wegener, Z. Yu, A. Kiendler-Scharr, A. Wahner and H. Fuchs, Importance of isomerization reactions for the $\mathrm{OH}$ radical regeneration from the photo-oxidation of isoprene investigated in the 
atmospheric simulation chamber SAPHIR, Atmos. Chem. Phys., 2020, 20, 3333-3355.

15 J. Lelieveld, T. M. Butler, J. N. Crowley, T. J. Dillon, H. Fischer, L. Ganzeveld, H. Harder, M. G. Lawrence, M. Martinez, D. Taraborrelli and J. Williams, Atmospheric oxidation capacity sustained by a tropical forest, Nature, 2008, 452, 737-740.

16 K. H. Møller, K. H. Bates and H. G. Kjaergaard, The importance of peroxy radical hydrogen-shift reactions in atmospheric isoprene oxidation, J. Phys. Chem. A, 2019, 123, 920-932.

17 T. Berndt, Formation of carbonyls and hydroperoxyenals (HPALDs) from the $\mathrm{OH}$ radical reaction of isoprene for lowNOx conditions: Influence of temperature and water vapour content, J. Atmos. Chem., 2012, 69, 253-272.

18 A. P. Teng, J. D. Crounse and P. O. Wennberg, Isoprene peroxy radical dynamics, J. Am. Chem. Soc., 2017, 139, 5367-5377.

19 J.-F. Müller, T. Stavrakou and J. Peeters, Chemistry and deposition in the model of atmospheric composition at global and regional scales using inversion techniques for trace gas emissions (MAGRITTE v1.1) - Part 1: Chemical mechanism, Geosci. Model Dev., 2019, 12, 2307-2356.

20 H. Fuchs, A. Hofzumahaus, F. Rohrer, B. Bohn, T. Brauers, H.-P. Dorn, R. Häseler, F. Holland, M. Kaminski, X. Li, K. Lu, S. Nehr, R. Tillmann, R. Wegener and A. Wahner, Experimental evidence for efficient hydroxyl radical regeneration in isoprene oxidation, Nat. Geosci., 2013, 6, 1023-1026.

21 V. S. Nguyen and J. Peeters, Fast $(E)-(Z)$ isomerization mechanisms of substituted allyloxy radicals in isoprene oxidation, J. Phys. Chem. A, 2015, 119, 7270-7276.

$22 \mathrm{~J}$. Peeters and T. L. Nguyen, Unusually fast 1,6-H shifts of enolic hydrogens in peroxy radicals: Formation of the firstgeneration $\mathrm{C} 2$ and $\mathrm{C} 3$ carbonyls in the oxidation of isoprene, J. Phys. Chem. A, 2012, 116, 6134-6141.

23 J. D. Crounse, F. Paulot, H. G. Kjaergaard and P. O. Wennberg, Peroxy radical isomerization in the oxidation of isoprene, Phys. Chem. Chem. Phys., 2011, 13, 13607-13613.

24 J. D. Crounse, L. B. Nielsen, S. Jørgensen, H. G. Kjaergaard and P. O. Wennberg, Autoxidation of organic compounds in the atmosphere, J. Phys. Chem. Lett., 2013, 4, 3513-3520.

25 G. da Silva, Oxidation of carboxylic acids regenerates hydroxyl radicals in the unpolluted and nighttime troposphere, J. Phys. Chem. A, 2010, 114, 6861-6869.

26 S. Wang, M. Riva, C. Yan, M. Ehn and L. Wang, Primary formation of highly oxidized multifunctional products in the $\mathrm{OH}$-initiated oxidation of isoprene: A combined theoretical and experimental study, Environ. Sci. Technol., 2018, 52, 12255-12264.

27 B. Nozière and L. Vereecken, Direct observation of aliphatic peroxy radical autoxidation and water effects: An experimental and theoretical study, Angew. Chem., Int. Ed., 2019, 58, 13976-13982.

28 E. Praske, R. V. Otkjær, J. D. Crounse, J. C. Hethcox, B. M. Stoltz, H. G. Kjaergaard and P. O. Wennberg,
Intramolecular hydrogen shift chemistry of hydroperoxysubstituted peroxy radicals, J. Phys. Chem. A, 2019, 123, 590-600.

29 L. Xu, K. H. Møller, J. D. Crounse, R. Otkær, H. G. Kjaergaard and P. O. Wennberg, Unimolecular reactions of peroxy radicals formed in the oxidation of $\alpha$-pinene and $\beta$-pinene by hydroxyl radicals, J. Phys. Chem. A, 2019, 123, 1661-1674.

30 R. V. Otkjær, H. H. Jakobsen, C. M. Tram and H. G. Kjaergaard, Calculated hydrogen shift rate constants in substituted alkyl peroxy radicals, J. Phys. Chem. A, 2018, 112, 8665-8673.

31 A. Miyoshi, Systematic computational study on the unimolecular reactions of alkylperoxy $\left(\mathrm{RO}_{2}\right)$, Hydroperoxyalkyl $(\mathrm{QOOH})$, and hydroperoxyalkylperoxy $\left(\mathrm{O}_{2} \mathrm{QOOH}\right)$ radicals, J. Phys. Chem. A, 2011, 115, 3301-3325.

32 S. Sharma, S. Raman and W. H. Green, Intramolecular hydrogen migration in alkylperoxy and hydroperoxyalkylperoxy radicals: Accurate treatment of hindered rotors, J. Phys. Chem. A, 2010, 114, 5689-5701.

33 L. Vereecken and B. Nozière, $\mathrm{H}$ migration in peroxy radicals under atmospheric conditions, Atmos. Chem. Phys., 2020, 20, 7429-7458.

34 M. E. Jenkin, S. M. Saunders and M. J. Pilling, The tropospheric degradation of volatile organic compounds: A protocol for mechanism development, Atmos. Environ., 1997, 31, 81-104.

35 S. M. Saunders, M. E. Jenkin, R. G. Derwent and M. J. Pilling, Protocol for the development of the Master Chemical Mechanism, MCM v3 (Part A): Tropospheric degradation of non-aromatic volatile organic compounds, Atmos. Chem. Phys., 2003, 3, 161-180.

36 M. E. Jenkin, J. C. Young and A. R. Rickard, The MCM v3.3.1 degradation scheme for isoprene, Atmos. Chem. Phys., 2015, 15, 11433-11459.

37 L. Vereecken, B. Aumont, I. Barnes, J. W. Bozzelli, M. J. Goldman, W. H. Green, S. Madronich, M. R. McGillen, A. Mellouki, J. J. Orlando, B. Picquet-Varrault, A. R. Rickard, W. R. Stockwell, T. J. Wallington and W. P. L. Carter, Perspective on mechanism development and structure-activity relationships for gas-phase atmospheric chemistry, Int. J. Chem. Kinet., 2018, 50, 435-469.

38 L. Vereecken and J. Peeters, Decomposition of substituted alkoxy radicals-part I: A generalized structure-activity relationship for reaction barrier heights, Phys. Chem. Chem. Phys., 2009, 11, 9062-9074.

39 T. Berndt and O. Böge, Gas-phase reaction of NO3 radicals with isoprene: A kinetic and mechanistic study, Int. J. Chem. Kinet., 1997, 29, 755-765.

40 I. Suh, W. Lei and R. Zhang, Experimental and theoretical studies of isoprene reaction with $\mathrm{NO}_{3}, J$. Phys. Chem. A, 2001, 105, 6471-6478.

41 A. W. Rollins, A. Kiendler-Scharr, J. L. Fry, T. Brauers, S. S. Brown, H.-P. Dorn, W. P. Dube, H. Fuchs, A. Mensah, T. F. Mentel, F. Rohrer, R. Tillmann, R. Wegener, P. J. Wooldridge and R. C. Cohen, Isoprene oxidation by 
nitrate radical: Alkyl nitrate and secondary organic aerosol yields, Atmos. Chem. Phys., 2009, 9, 6685-6703.

42 R. H. Schwantes, A. P. Teng, T. B. Nguyen, M. M. Coggon, J. D. Crounse, J. M. St Clair, X. Zhang, K. A. Schilling, J. H. Seinfeld and P. O. Wennberg, Isoprene $\mathrm{NO}_{3}$ oxidation products from the $\mathrm{RO}_{2}+\mathrm{HO}_{2}$ pathway, J. Phys. Chem. A, 2015, 119, 10158-10171.

43 A. J. Kwan, A. W. H. Chan, N. L. Ng, H. G. Kjaergaard, J. H. Seinfeld and P. O. Wennberg, Peroxy radical chemistry and $\mathrm{OH}$ radical production during the $\mathrm{NO}_{3}$-initiated oxidation of isoprene, Atmos. Chem. Phys., 2012, 12, 7499-7515.

44 E. S. C. Kwok, S. M. Aschmann, J. Arey and R. Atkinson, Product formation from the reaction of the $\mathrm{NO}_{3}$ radical with isoprene and rate constants for the reactions of methacrolein and methyl vinyl ketone with the $\mathrm{NO}_{3}$ radical, Int. J. Chem. Kinet., 1996, 28, 925-934.

45 D. Casanova, F. P. Rotzinger and M. Graetzel, Computational study of promising organic dyes for high-performance sensitized solar cells, J. Chem. Theory Comput., 2010, 6, 1219-1227.

46 P. Dewald, J. M. Liebmann, N. Friedrich, J. Shenolikar, J. Schuladen, F. Rohrer, D. Reimer, R. Tillmann, A. Novelli, C. Cho, K. Xu, R. Holzinger, F. Bernard, L. Zhou, W. Mellouki, S. S. Brown, H. Fuchs, J. Lelieveld and J. N. Crowley, Evolution of $\mathrm{NO}_{3}$ reactivity during the oxidation of isoprene, Atmos. Chem. Phys., 2020, 20, 10459-10475.

47 M. A. H. Khan, B.-L. Schlich, M. E. Jenkin, M. C. Cooke, R. G. Derwent, J. L. Neu, C. J. Percival and D. E. Shallcross, Changes to simulated global atmospheric composition resulting from recent revisions to isoprene oxidation chemistry, Atmos. Environ., 2021, 244, 117914.

$48 \mathrm{~J}$. Zhao and R. Zhang, A theoretical investigation of nitrooxyalkyl peroxy radicals from NO3-initiated oxidation of isoprene, Atmos. Environ., 2008, 42, 5849-5858.

49 A. Novelli, C. Cho, H. Fuchs, A. Hofzumahaus, F. Rohrer, R. Tillmann, A. Kiendler-Scharr, A. Wahner and L. Vereecken, Experimental and theoretical study on the impact of a nitrate group on the chemistry of alkoxy radicals, Phys. Chem. Chem. Phys., 2021, DOI: 10.1039/d0cp05555g.

50 T. H. Dunning, Gaussian basis sets for use in correlated molecular calculations. I. The atoms boron through neon and hydrogen, J. Chem. Phys., 1989, 90, 1007-1023.

51 Y. Zhao and D. G. Truhlar, The M06 suite of density functionals for main group thermochemistry, thermochemical kinetics, noncovalent interactions, excited states, and transition elements: Two new functionals and systematic testing of four M06-class functionals and 12 other functionals, Theor. Chem. Acc., 2008, 120, 215-241.

52 G. D. Purvis and R. J. Bartlett, A full coupled-cluster singles and doubles model: The inclusion of disconnected triples, J. Chem. Phys., 1982, 76, 1910.

53 I. M. Alecu, J. Zheng, Y. Zhao and D. G. Truhlar, Computational thermochemistry: Scale factor databases and scale factors for vibrational frequencies obtained from electronic model chemistries, J. Chem. Theory Comput., 2010, 6, 2872-2887.
54 J. L. Bao, J. Zheng, I. M. Alecu, B. J. Lynch, Y. Zhao and D. G. Truhlar, Database of Frequency Scale Factors for Electronic Model Chemistries (Version 4), http://comp. chem.umn.edu/freqscale/index.html.

55 M. J. Frisch, G. W. Trucks, H. B. Schlegel, G. E. Scuseria, M. A. Robb, J. R. Cheeseman, G. Scalmani, V. Barone, B. Mennucci, G. A. Petersson, H. Nakatsuji, X. Li, M. Caricato, A. V. Marenich, J. Bloino, B. G. Janesko, R. Gomperts, B. Mennucci, H. P. Hratchian, J. V. Ortiz, A. F. Izmaylov, J. L. Sonnenberg, D. Williams-Young, F. Ding, F. Lipparini, F. Egidi, J. Goings, B. Peng, A. Petrone, T. Henderson, D. Ranasinghe, V. G. Zakrzewski, J. Gao, N. Rega, G. Zheng, W. Liang, M. Hada, M. Eara, K. Toyota, R. Fukuda, J. Hasegawa, M. Ishida, T. Nakajima, Y. Honda, O. Kitao, H. Nakai, T. Vreven, K. Throssell, J. A. Mntgomery, Jr., J. E. Peralta, F. Ogliaro, M. J. Bearpark, J. J. Heyd, E. N. Brothers, K. N. Kudin, V. N. Staroverov, T. A. Keith, R. Kobayashi, J. Normand, K. Raghavachari, A. P. Rendell, J. C. Burant, S. S. Iyengar, J. Tomasi, M. Cossi, J. M. Millam, M. Klene, C. Adamo, R. Cammi, J. W. Ochterski, R. L. Martin, K. Morokuma, O. Farkas, J. B. Foresman and D. J. Fox, Gaussian 16, Revision B.01, Gaussian Inc., Wallington, CT, 2016.

56 D. G. Truhlar, B. C. Garrett and S. J. Klippenstein, Current status of transition-state theory, J. Phys. Chem., 1996, 100, 12771-12800.

57 L. Vereecken and J. Peeters, The 1,5-H-shift in 1-butoxy: A case study in the rigorous implementation of transition state theory for a multirotamer system, J. Chem. Phys., 2003, 119, 5159-5170.

58 C. Eckart, The penetration of a potential barrier by electrons, Phys. Rev., 1930, 35, 1303-1309.

59 H. S. Johnston and J. Heicklen, Tunneling corrections for unsymmetrical Eckart potential energy barriers, J. Phys. Chem., 1962, 66, 532-533.

60 L. Vereecken and J. Peeters, A structure-activity relationship for the rate coefficient of H-migration in substituted alkoxy radicals, Phys. Chem. Chem. Phys., 2010, 12, 12608-12620.

61 L. Vereecken, A. Novelli and D. Taraborrelli, Unimolecular decay strongly limits concentration of Criegee intermediates in the atmosphere, Phys. Chem. Chem. Phys., 2017, 19, 31599-31612.

62 L. Vereecken, G. Huyberechts and J. Peeters, Stochastic simulation of chemically activated unimolecular reactions, J. Chem. Phys., 1997, 106, 6564-6573.

63 F. Rohrer, B. Bohn, T. Brauers, D. Bruning, F. J. Johnen, A. Wahner and J. Kleffmann, Characterisation of the photolytic HONO-source in the atmosphere simulation chamber SAPHIR, Atmos. Chem. Phys., 2005, 5, 2189-2201.

64 D. Poppe, T. Brauers, H.-P. Dorn, M. Karl, T. Mentel, E. Schlosser, R. Tillmann, R. Wegener and A. Wahner, $\mathrm{OH}$-Initiated degradation of several hydrocarbons in the atmosphere simulation chamber SAPHIR, J. Atmos. Chem., 2007, 57, 203-214.

65 E. Schlosser, B. Bohn, T. Brauers, H.-P. Dorn, H. Fuchs, R. Haeseler, A. Hofzumahaus, F. Holland, F. Rohrer, L. O. Rupp, M. Siese, R. Tillmann and A. Wahner, 
Intercomparison of two hydroxyl radical measurement techniques at the atmosphere simulation chamber SAPHIR, J. Atmos. Chem., 2007, 56, 187-205.

66 F. Holland, A. Hofzumahaus, R. Schafer, A. Kraus and H. W. Patz, Measurements of $\mathrm{OH}$ and $\mathrm{HO}_{2}$ radical concentrations and photolysis frequencies during BERLIOZ, J. Geophys. Res.: Atmos., 2003, 108, 8246.

67 H. Fuchs, B. Bohn, A. Hofzumahaus, F. Holland, K. D. Lu, S. Nehr, F. Rohrer and A. Wahner, Detection of $\mathrm{HO}_{2}$ by laserinduced fluorescence: Calibration and interferences from $\mathrm{RO}_{2}$ radicals, Atmos. Meas. Tech., 2011, 4, 1209-1225.

68 L. K. Whalley, M. A. Blitz, M. Desservettaz, P. W. Seakins and D. E. Heard, Reporting the sensitivity of laser-induced fluorescence instruments used for $\mathrm{HO}_{2}$ detection to an interference from $\mathrm{RO}_{2}$ radicals and introducing a novel approach that enables $\mathrm{HO}_{2}$ and certain $\mathrm{RO}_{2}$ types to be selectively measured, Atmos. Meas. Tech., 2013, 6, 3425-3440.

69 T. S. Dibble, Isomerization of $\mathrm{OH}$-isoprene adducts and hydroxyalkoxy isoprene radicals, J. Phys. Chem. A, 2002, 106, 6643-6650.

70 H. Fuchs, S. Albrecht, I. Acir, B. Bohn, M. Breitenlechner, H.-P. Dorn, G. I. Gkatzelis, A. Hofzumahaus, F. Holland, M. Kaminski, F. N. Keutsch, A. Novelli, D. Reimer, F. Rohrer, R. Tillmann, L. Vereecken, R. Wegener, A. Zaytsev, A. KiendlerScharr and A. Wahner, Investigation of the oxidation of methyl vinyl ketone (MVK) by $\mathrm{OH}$ radicals in the atmospheric simulation chamber SAPHIR, Atmos. Chem. Phys., 2018, 18, 8001-8016.

71 X. T. Le, T. V.-T. Mai, K. C. Lin and L. K. Huynh, Low temperature oxidation kinetics of biodiesel molecules: Rate rules for concerted $\mathrm{HO}_{2}$ elimination from alkyl ester peroxy radicals, J. Phys. Chem. A, 2018, 122(42), 8259-8273.

72 J. A. Miller and S. J. Klippenstein, The reaction between ethyl and molecular oxygen II: Further analysis, Int. J. Chem. Kinet., 2001, 33, 654-668.

73 S. M. Villano, L. K. Huynh, H.-H. Carstensen and A. M. Dean, High-pressure rate rules for alkyl $+\mathrm{O}_{2}$ reactions. 1 . The dissociation, concerted elimination, and isomerization channels of the alkyl peroxy radical, J. Phys. Chem. A, 2011, 115, 13425-13442.

74 T. L. Nguyen, L. Vereecken and J. Peeters, HOx Regeneration in the oxidation of isoprene III: Theoretical study of the key isomerisation of the $Z$ - $\delta$-hydroxy-peroxy isoprene radicals, ChemPhysChem, 2010, 11, 3996-4001.

75 L. Vereecken, in Advances in Atmospheric Chemistry, Organic Oxidation and Multiphase Chemistry, ed. J. R. Barker, A. L. Steiner and T. J. Wallington, World Scientific
Publishing Co. Pte. Ltd, Singapore, 1st edn, 2019, vol. 2, pp. $377-527$.

76 L. Wang, R. Wu and C. Xu, Atmospheric oxidation mechanism of benzene. Fates of alkoxy radical intermediates and revised mechanism, J. Phys. Chem. A, 2013, 117, 14163-14168.

77 C. A. Whelan, M. A. Blitz, R. Shannon, L. Onel, J. P. Lockhart, P. W. Seakins and D. Stone, Temperature and pressure dependent kinetics of $\mathrm{QOOH}$ decomposition and reaction with $\mathrm{O}_{2}$ : Experimental and theoretical investigations of QOOH radicals derived from $\mathrm{Cl}+\left(\mathrm{CH}_{3}\right)_{3} \mathrm{COOH}$, J. Phys. Chem. A, 2019, 123, 10254-10262.

78 T. M. Lenhardt, C. E. Mcdade and K. D. Bayes, Rates of reaction of butyl radicals with molecular-oxygen, J. Chem. Phys., 1980, 72, 304-310.

79 IUPAC Subcommittee on Atmospheric Chemical Kinetic Data Evaluation, Evaluated Kinetic Data, 2017, available at: http:// iupac.pole-ether.fr/index.html.

80 J. Zádor, H. Huang, O. Welz, J. Zetterberg, D. L. Osborn and C. A. Taatjes, Directly measuring reaction kinetics of -QOOH - A crucial but elusive intermediate in hydrocarbon autoignition, Phys. Chem. Chem. Phys., 2013, 15, 10753-10760.

81 M. E. Jenkin, R. Valorso, B. Aumont and A. R. Rickard, Estimation of rate coefficients and branching ratios for reactions of organic peroxy radicals for use in automated mechanism construction, Atmos. Chem. Phys., 2019, 19, 7691-7717.

82 T. Kurtén, K. H. Møller, T. B. Nguyen, R. H. Schwantes, P. K. Misztal, L. Su, P. O. Wennberg, J. L. Fry and H. G. Kjaergaard, Alkoxy radical bond scissions explain the anomalously low secondary organic aerosol and organonitrate yields from $\alpha$-pinene $+\mathrm{NO}_{3}, J$. Phys. Chem. Lett., 2017, 8, 2826-2834.

83 A. S. Hasson, G. S. Tyndall, J. J. Orlando, S. Singh, S. Q. Hernandez, S. Campbell and Y. Ibarra, Branching ratios for the reaction of selected carbonyl-containing peroxy radicals with hydroperoxy radicals, J. Phys. Chem. A, 2012, 116, 6264-6281.

84 J.-P. Le Crâne, M.-T. Rayez, J.-C. Rayez and E. Villenave, A reinvestigation of the kinetics and the mechanism of the $\mathrm{CH}_{3} \mathrm{C}(\mathrm{O}) \mathrm{O}_{2}+\mathrm{HO}_{2}$ reaction using both experimental and theoretical approaches, Phys. Chem. Chem. Phys., 2006, 8, 2163-2171.

85 H. Fuchs, F. Holland and A. Hofzumahaus, Measurement of tropospheric $\mathrm{RO}_{2}$ and $\mathrm{HO}_{2}$ radicals by a laser-induced fluorescence instrument, Rev. Sci. Instrum., 2008, 79, 084104.

86 T. Berndt, N. Hyttinen, H. Herrmann and A. Hansel, First oxidation products from the reaction of hydroxyl radicals with isoprene for pristine environmental conditions, Chem. Commun., 2019, 2, 21. 